\title{
Plenum Pressure Behavior in Transiently Heat Loaded Transpiration Cooling System
}

\author{
Fabian Hufgard * and Stefan Loehle ${ }^{\dagger}$ \\ High Enthalpy Flow Diagnostics Group HEFDiG, Institute of Space Systems, 70569 Stuttgart, Germany \\ Matthew McGilvray ${ }^{\ddagger}$ and Tobias Hermann ${ }^{\S}$ \\ University of Oxford, Oxford OX2 OES, United Kingdom \\ Sven Schweikert ${ }^{\text {Il }}$ and Jens von Wolfersdorf ${ }^{\|}$ \\ Institute of Aerospace Thermodynamics, 70569 Stuttgart, Germany \\ Johan Steelant** \\ ESA-ESTEC, 2200 AG Noordwijk, The Netherlands \\ Stefanos Fasoulas ${ }^{\dagger \dagger}$ \\ Institute of Space Systems, 70569 Stuttgart, Germany
}

In this paper the behavior of the plenum pressure behind a transpiration cooled porous material sample after an incident surface heat flux to the sample is analyzed in experiment and theory. Two porous materials, zirconium diboride and carbon/carbon, were characterized using the Pressure-Based Non-Integer System Identification method. The resulting impulse responses are analyzed based on two numerical models. One model calculates a plenum pressure impulse response by modelling the porous sample's heat conduction. A second model considers an additional plenum behind the sample and allowing a changing mass flow rate through the sample. The experimentally obtained impulse responses show a stronger response for increasing coolant mass flow rates. Both models cover this trend essentially depending on the volumetric heat transfer coefficient. However, only the second model allows the entire rebuilding of the experimental data. The plenum pressure impulse response for a transpiration cooled system depends not only on the material parameters of the porous sample, but also on the volume of the plenum. The reason is that the flow rate changes through the porous sample although the mass flow rate at the controller always stays constant.

\footnotetext{
*PhD Student, High Enthalpy Flow Diagnostics Group HEFDiG, Institute of Space Systems, Pfaffenwaldring 29, 70569 Stuttgart, Germany.

${ }^{\dagger}$ Head of the High Enthalpy Flow Diagnostics Group HEFDiG, Institute of Space Systems, Pfaffenwaldring 29, 70569 Stuttgart, Germany, AIAA senior member.

${ }^{\ddagger}$ Associate professor, Hypersonics Group, Osney Thermofluids Institute, Osney Mead, The Southwell Building, Oxford, United Kingdom, AIAA member.

${ }^{\S}$ Post-doctoral research assistant, Hypersonics Group, Osney Thermofluids Institute, Osney Mead, The Southwell Building, Oxford, United Kingdom, AIAA member.

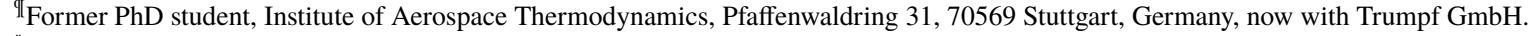

"Professor, Institute of Aerospace Thermodynamics, Pfaffenwaldring 31, 70569 Stuttgart, Germany, AIAA member.

**Professor and senior research scientist, Flight Vehicles and Aerothermodynamics Engineering Section, Keplerlaan 1, P.O. Box 299, 2200 AG Noordwijk, The Netherlands.

${ }^{\dagger}$ Professor, Director Institute of Space Systems, Pfaffenwaldring 29, 70569 Stuttgart, Germany, AIAA member.
} 


\section{Nomenclature}

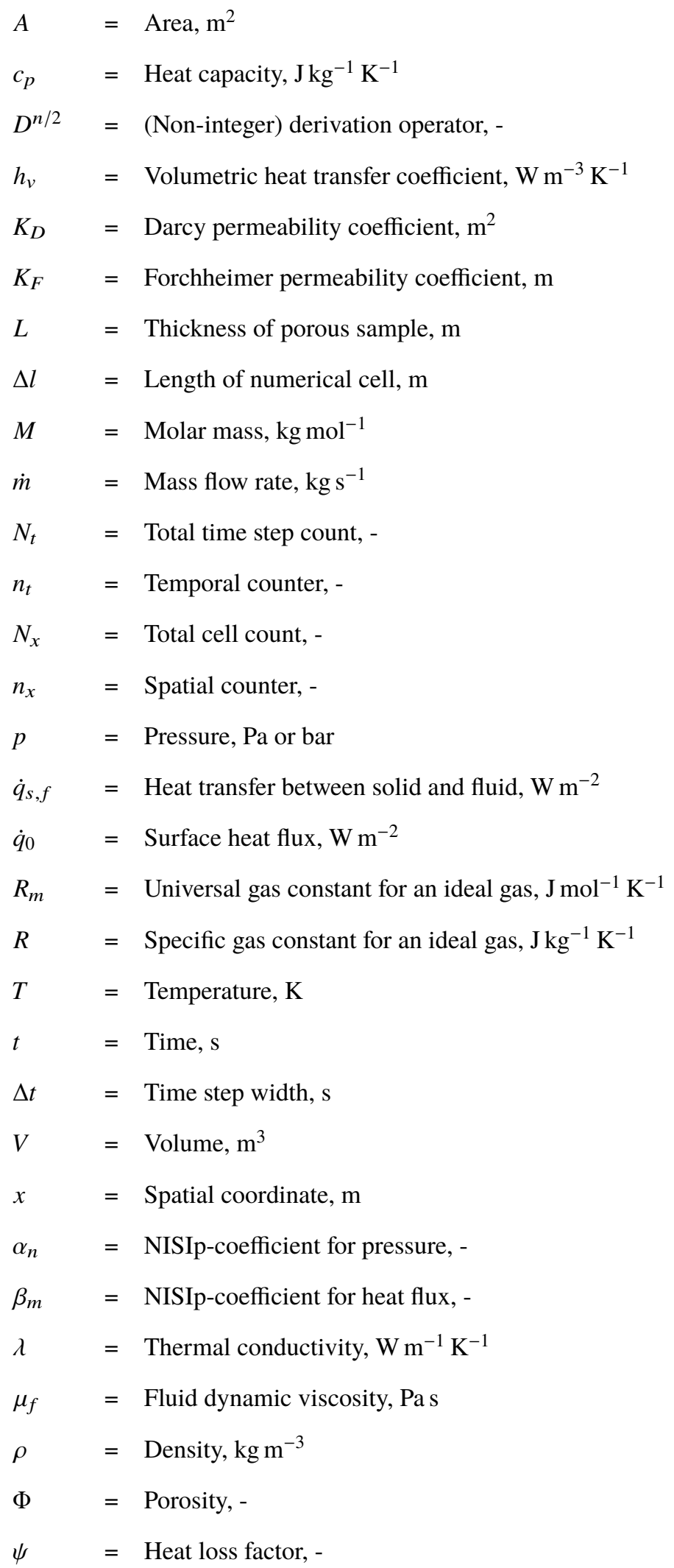




$\begin{array}{ll}\text { Subscripts } & \\ \text { amb } & =\text { Ambient } \\ \text { conv } & =\text { Convective } \\ e & =\text { Effective } \\ \text { exp } & =\text { Experiment } \\ f & =\text { Fluid } \\ f c & =\text { Flow controller } \\ \text { in } & =\text { Inbound flow } \\ \text { initial } & =\text { Initial } \\ m & =\text { Spatially mean value } \\ \text { out } & =\text { Outbound flow } \\ p l & =\text { Plenum } \\ p s & =\text { Porous sample } \\ s & =\text { Solid }\end{array}$

\section{Introduction}

EROSPACE applications such as heat shields of re-entry vehicles or the internal wall structures of combustion
chambers for rockets are commonly subject to extreme surface heat flux, which necessitates active cooling for some applications [1-3]. One active cooling technology is transpiration cooling, which has expanded its applicability through the development of high temperature porous materials [4-10]. Examples for transpiration cooling applications are heat shields of reentry vehicles and combustion engines [10-14]. Transpiration cooling means that a gaseous or liquid coolant is fed through the wall, which consists of a porous material, into the hot gas region. This has two effects: Firstly, the wall is actively cooled by the coolant, where the thermal energy is fed back into the hot gas region. Secondly, the coolant acts like an additional heat shield by forming a layer of comparatively cold gas between wall and hot gas and thus reducing the surface heat flux by convection. A detailed description of this process can be found in [11] and references therein.

An assessment of the performance of transpiration cooled applications requires a thorough characterization of the transpiration cooling by distinct measurements. One essential value is the net surface heat flux entering the material. Measurement of surface heat flux is still a challenging endeavour, especially in transpiration cooling environments. Classical methods for surface heat flux determination as in $[15,16]$ fail in such a scenario, because of the coupled heat transfer between solid and fluid [17]. One method capable of heat flux measurements in transpiration cooled environments is the Non-Integer System Identification (NISI) method [18]. It has been developed by the High Enthalpy 
Flow Diagnostics Group (HEFDiG) at the Institute of Space Systems of the University of Stuttgart [19-21]. The fundamental advantage of the NISI method is that the respective sensor system is fully characterized by non-destructive calibration of the actual hardware. By application of a well-known surface heat flux and measurement of the temporal temperature profile, the given system can be characterized. The resulting system-specific transfer function is used for the calculation of the temporal temperature profile induced by a numerical Dirac heat impulse. This temperature profile equals the system's impulse response, which fully describes the temporal behavior of the system [22]. The effect of various material parameters on a system's temperature impulse response was studied in [23]. If the impulse response is known, a single calibrated temperature sensor suffices for the inverse determination of surface heat flux without detailed knowledge of thermophysical properties or geometry of the sensor [19, 24]. The NISI method has been enhanced to data analysis for transpiration cooled environments [18, 23, 25]. However, boreholes can decrease the structural performance. Also, glueing the thermocouple into the porous material implies uncertainties regarding flow field disruption around the spot of the temperature measurement itself. Although this is taken into account by NISI, it can be disadvantageous for the cooling performance.

Figure 1 sketches a transpiration cooling system, where a coolant transpires from a plenum through a porous wall. Its surface is affected by a heat flux $\dot{q}_{0}(t)$. It was found that in such a system, the plenum pressure is sensitive to the surface heat flux and the NISI method can be applied using the measured plenum pressure as the sensor signal [26]. So, the surface heat flux can be determined by measurement of plenum pressure only.

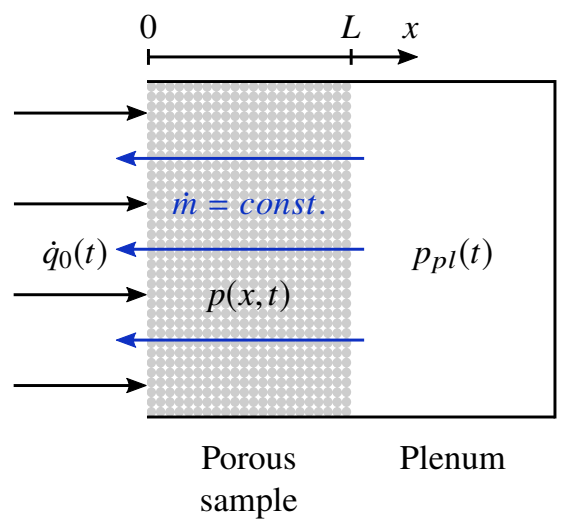

Fig. 1 Heat conduction scenario for a transpiration cooled porous material with constant mass flow rate through porous sample [26].

The sensitivity of plenum pressure to surface heat flux has been explained by the temperature and viscosity increase of the coolant while passing the porous wall [26]. Applying a surface heat flux results in a temperature increase of the porous wall. The heat is conducted into the material and the coolant consumes some of this heat while passing toward 
the surface resulting in a coolant temperature increase. For the 1D problem, the relation of temperature $T(x, t)$ and pressure $p(x, t)$ of the fluid within the porous wall is given by the rearranged Darcy-Forchheimer equation:

$$
p \frac{\partial p}{\partial x}(x, t)=\frac{\mu_{f}(T(x, t)) \dot{m} R T(x, t)}{K_{D} A}+\frac{\dot{m}^{2} R T(x, t)}{K_{F} A^{2}}, \quad(x, t) \geq 0
$$

with spatial and temporal variables $x$ and $t$. The mass flow rate $\dot{m}$, the specific gas constant for an ideal gas $R$, the porous wall cross sectional area $A$ and the material characteristic permeability coefficients $K_{D}$ and $K_{F}$ are assumed constant. The fluid's viscosity $\mu_{f}$ is a function of the fluid's temperature. This relation can be described, for example, by a power law or the Sutherland formulation. Hence, the local pressure $p(x, t)$ is a function of coolant temperature $T(x, t)$. Because pressure is an intensive value, a local pressure increase is also detected at the far end of the porous sample, i.e. in the plenum [26].

In this paper the relation of surface heat flux to plenum pressure is further investigated by comparing experimentally obtained plenum pressure impulse responses to numerical simulations. The experiments featured two porous materials: zirconium diboride $\left(\mathrm{ZrB}_{2}\right)$ and carbon/carbon $(\mathrm{C} / \mathrm{C})$. The experimental setups are described in section III. The PressureBased Non-Integer System Identification method (NISIp), which is reviewed in section II, was used for the determination of impulse responses from experimental data (cf. section IV). Section V addresses the design and results of two developed numerical models. These numerical models aid the understanding of the measured plenum pressure impulse response and allow the conclusion that the enhancement of the heat conduction scenario shown in Fig. 1 by a finite plenum volume bounded at the backside by the mass flow controller is essential.

\section{Pressure-Based Non-Integer System Identification}

In a transpiration cooling scenario as sketched in Fig. 1, the relation between plenum pressure $p_{p l}$ and surface heat flux $\dot{q}_{0}$ can be written as

$$
\sum_{n=N_{0}}^{N} \alpha_{n} D^{n / 2} p_{p l}(t)=\sum_{m=M_{0}}^{M} \beta_{m} D^{m / 2} \dot{q}_{0}(t) \quad \text { with } \quad \alpha_{N_{0}}=1
$$

with model parameters $\alpha_{n}$ and $\beta_{m}$ and the (non-integer) time derivations $D$ of the order $n / 2$ and $m / 2$ respectively [26]. The Pressure-Based Non-Integer System Identification Approach (NISIp) is used for the characterization of the transpiration cooling system. A known heat flux is applied to the surface while the plenum pressure is measured. The identification of the unknown parameters $\alpha_{n}$ and $\beta_{m}$ in Eq. (2) is solved by rebuilding the measured plenum pressure signal using a least-squares method. The implementation of this approach in usable computer code is described in detail by Battaglia et al. [19] and Gardarein et al. [21]. The non-integer derivatives are calculated using an algorithm by Grünwald and Letnikov as given in [27]. The identified set of parameters is then used to calculate the temporal evolution 
$p_{p l}(t)$ of a Dirac impulse, that is a heat pulse of $1 \mathrm{~J} \mathrm{~m}^{-2}$. The resulting temporal plenum pressure profile represents the system's impulse response, which fully characterizes the given system [22].

\section{Experimental Setup}

In this paper, the results of investigations of two different porous materials, zirconium diboride $\left(\mathrm{ZrB}_{2}\right)$ and carbon/carbon $(\mathrm{C} / \mathrm{C})$, are compared. Conceptionally the respective setups for both test campaigns were equal. A square-shaped porous sample was mounted within a metal sample holder and sealed at the edges. A gaseous coolant was fed through a mass flow controller into a plenum behind the porous sample. After transpiring through the porous sample the coolant exited towards ambient conditions. For both campaigns, the gas supply pressure was 8 bar. The transient plenum pressure is measured using a commercial gauge. Radiative heating is provided by a diode laser system (Laserline LDM 500-100). The laser wavelength is $910 \mathrm{~nm}$ and its power rise time is specified $<0.1 \mathrm{~ms}$. The laser power is adjusted with the manufacturer's calibration information from the power setting. The focusing optics expanded the laser beam homogeneously into a square-shaped spot. In both experiments the radiated area was larger than the porous material's surface and thus overlapped to all sides in order to minimise lateral conduction. The effect of the remaining lateral conduction is addressed in subsection V.C.3. Both the laser input power and the pressure signal were recorded using an oscilloscope (LeCroy 24Xs-A).

Table 1 gives the material characteristics of the analysed porous samples. Note, that thermal conductivity given in Table 1 means the effective thermal conductivity of the porous material (without fluid) defined by $\lambda_{e}=(1-\Phi) \lambda_{\text {massive }}$ [28]. Likewise, the density $\rho_{e}$ is the effective density of the porous material.

Table 1 Material properties and geometry of the porous samples.

\begin{tabular}{cccccccc}
\hline & $\Phi, \%$ & $K_{D}, 10^{-14} \mathrm{~m}^{2}$ & $K_{F}, 10^{-9} \mathrm{~m}$ & $\lambda_{e}, \mathrm{~W} \mathrm{~m}^{-1} \mathrm{~K}^{-1}$ & $\rho_{e}, \mathrm{~kg} \mathrm{~m}^{-3}$ & $c_{p}, \mathrm{~J} \mathrm{~kg}^{-1} \mathrm{~K}^{-1}$ & $A \times L, \mathrm{~mm}^{3}$ \\
\hline $\mathrm{ZrB}_{2}$ & 42 & $2.44[6]$ & $88.6[6]$ & 24.0 & 3526 & $437.6[29]$ & $32 \times 32 \times 5$ \\
$\mathrm{C} / \mathrm{C}$ & $12.4[30]$ & 20.0 & 9.1 & $1.75[31]$ & 1375 & $950[31]$ & $50 \times 50 \times 11.16$ \\
\hline
\end{tabular}

The partially sintered $\mathrm{ZrB}_{2}$ sample was manufactured at the Department of Materials of Imperial College London. The material properties, which are listed in Table 1, were also characterized there. The given permeability properties were characterized by the Hypersonics Group at the Oxford Thermofluids Institute [6]. The sample's area and thickness is $32 \times 32 \mathrm{~mm}^{2}$ and $5 \mathrm{~mm}$. In the measurement campaign with this sample, nitrogen was chosen as the coolant. The coolant mass flow rate was controlled by a Bronkhorst $1 \mathrm{~g} \mathrm{~s}^{-1}$ mass flow controller with an accuracy of $6 \mathrm{mg} \mathrm{s}^{-1}$. The pressure gauge used was a GEMS 3100 Series ( 0 - 40 bar) with a response time of $1 \mathrm{~ms}$ and an accuracy of the absolute pressure measurement of 0.1 bar. This accuracy is less relevant, since the NISIp method uses a differential pressure measurement to the initial value. The volume of the plenum for these experiments was approximately $6.2 \cdot 10^{-4} \mathrm{~m}^{3}$. Here a large uncertainty applies because the plenum volume size was not determined when the experimental setups 
were assembled and had to be estimated in retrospective. A layer of cement was used as sealant between the porous sample and the sample holder. The area of the laser spot was set to $68 \times 68 \mathrm{~mm}^{2}$. The absorptivity of $\mathrm{ZrB}_{2}$ at the laser wavelength is $0.75[32,33]$.

The $\mathrm{C} / \mathrm{C}$ sample's area was $50 \times 50 \mathrm{~mm}^{2}$ and it was $11.16 \mathrm{~mm}$ thick. It was manufactured at the German Aerospace Center (DLR) in Stuttgart. It is mainly used for surface heat flux measurements in a hot gas test facility at the Institute of Aerospace Thermodynamics (ITLR) of the University of Stuttgart [34]. The material parameters of the sample were characterised by ITLR and are listed in Table 1. The coolant used for these calibration measurements was air, which was controlled by a HFC-303, Teledyne-Hastings mass flow controller $\left(0-10.75 \mathrm{~g} \mathrm{~s}^{-1}\right)$ with an accuracy of $54 \mathrm{mg} \mathrm{s}^{-1}$. The plenum pressure was recorded using a Newport Omega PAA33X-C-15 gauge ( 0 - 15 bar $)$ with an accuracy of $7.5 \mathrm{mbar}$ and a response time of $2.5 \mathrm{~ms}$. Here, the plenum volume was approximately $4.5 \cdot 10^{-4} \mathrm{~m}^{3}$. Similar to the $\mathrm{ZrB}_{2}$ experimental setup, a large uncertainty is introduced through the retrospective estimation of the plenum volume size. The porous $\mathrm{C} / \mathrm{C}$ sample was edged by a copper lip, which was galvanized onto the $\mathrm{C} / \mathrm{C}$ The laser heat load was homogeneously distributed over an $80 \times 80 \mathrm{~mm}^{2}$ area. The absorptivity of $\mathrm{C} / \mathrm{C}$ at the laser wavelength is 0.88 [11].

\section{Plenum Pressure Impulse Responses from Experimental Data}

This section addresses the determination of impulse responses from experimental data. The results will show, that the impulse response magnitude and shape is highly dependant on the coolant mass flow rate. In the following, these impulse responses are used as reference data for the validation of two numerical models in section V.

In Fig. 2 the measured data of the calibration experiments for both investigated materials, $\mathrm{ZrB}_{2}$ (left plot) and $\mathrm{C} / \mathrm{C}$ (right plot) are shown. Relevant data for the calibration are the heat flux and the plenum pressure difference $\Delta p_{c a l}$. Note, that $\Delta p_{c a l}$ and all pressure data throughout this paper are pressure differences to the respective initial pressure of the experiment, i.e. $\Delta p(t)=p(t)-p(0)$. The coolant mass flow rate setting is the respective mass flow controller value $\dot{m}_{f c}$. This value can be different to the mass flow rate through the porous sample $\dot{m}_{p s}$ as argued in subsection V.C.1.

The heat flux profiles have been chosen randomly with a nominal net surface heat flux of $43 \mathrm{~kW} \mathrm{~m}^{-2}\left(\mathrm{ZrB}_{2}\right)$ and $60 \mathrm{~kW} \mathrm{~m}^{-2}$ (C/C). It can be observed in both plots of Fig. 2 that the pressure increases due to a heat flux at the surface. Whilst for the $\mathrm{C} / \mathrm{C}$ sample even short pulses are well distinguishable by a measured plenum pressure change, the short pulses in the left plot hardly imply a noticeable effect. Hence, the $\mathrm{ZrB}_{2}$ system appears to react slower to heat flux changes. This behavior is explained through the larger plenum volume of the $\mathrm{ZrB}_{2}$ system. A larger plenum volume size has a time delaying effect on the plenum pressure increase. This effect is addressed in subsection V.C.3. The total length of the measurement is therefore longer in the measurement campaign with $\mathrm{ZrB}_{2}$. In the left plot of Fig. 2, the sensitivity and pressure change increases with flow rate. As can be seen in the right plot, the pressure change reaches a maximum at a flow rate of $995 \mathrm{mg} \mathrm{s}^{-1}$ and decreases then with increasing flow rates. 

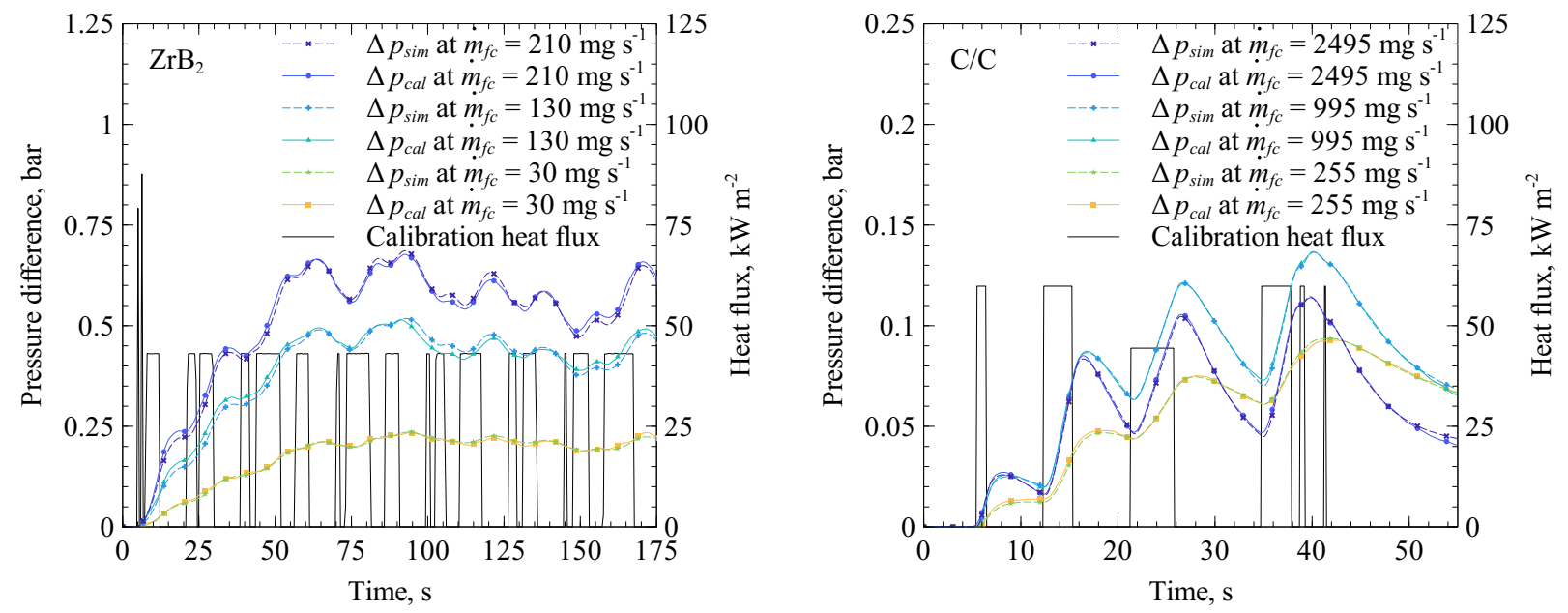

Fig. 2 For both transpiration cooling experiments with $\mathrm{ZrB}_{2}$ (left) and $\mathrm{C} / \mathrm{C}$ (right), the applied calibration heat flux, three exemplary calibration data sets (solid lines) and simulated pressure profiles resulting from the NISI identification step (dashed lines).

The calibration data are used for the identification of the NISIp parameters $\alpha_{n}$ and $\beta_{m}$ (see Eq. (2)). The least-squares fit $\left(\Delta p_{\text {sim }}\right)$ of the identified parameter set are shown as dashed lines in Fig. 2. As can be seen, a good agreement between the NISIp-identification and the measurement data is obtained for both systems, meaning all systems can be well identified.

The transfer function is built between heat flux and pressure difference according to Eq. (2). For all mass flow rates tested in the $\mathrm{ZrB}_{2}$ experiment, nine sum terms on the pressure side and ten on the heat flux side were used. Using Eq. (3) the measured pressure data were reproduced (see Fig. 2) resulting in a separate parameter set $\left(\alpha_{n}\right.$ and $\left.\beta_{m}\right)$ for each mass flow rate. The full list of parameters can be seen in Table 3.

$$
\begin{array}{r}
\left(\alpha_{1} D^{-0.5}+\alpha_{2}+\alpha_{3} D^{0.5}+\alpha_{4} D+\alpha_{5} D^{1.5}+\alpha_{6} D^{2}+\alpha_{7} D^{2.5}+\alpha_{8} D^{3}+\alpha_{9} D^{3.5}\right) p_{p l}(t) \\
=\left(\beta_{1}+\beta_{2} D^{0.5}+\beta_{3} D+\beta_{4} D^{1.5}+\beta_{5} D^{2}+\beta_{6} D^{2.5}+\beta_{7} D^{3}+\beta_{8} D^{3.5}+\beta_{9} D^{4}+\beta_{10} D^{4.5}\right) \dot{q}_{0}(t)
\end{array}
$$

Analogously, the polynomial order shown in Eq. (4) was used for the reproduction of the C/C pressure data. The corresponding parameters are listed in Table 4.

$$
\left(\alpha_{1}+\alpha_{2} D^{0.5}+\alpha_{3} D+\alpha_{4} D^{1.5}+\alpha_{5} D^{2}\right) p_{p l}(t)=\left(\beta_{1} D^{-0.5}+\beta_{2}+\beta_{3} D^{0.5}+\beta_{4} D\right) \dot{q}_{0}(t)
$$

Using these identified systems, the impulse responses shown in Fig. 3 were calculated for each coolant mass flow rate. Here, the required heat flux impulse was realized by a numerical implementation of a Dirac impulse, i.e. $1 \mathrm{~J} \mathrm{~m}^{-2}$. This procedure allows for a direct comparison of the resulting impulse responses as the same area specific energy is applied to the system. The time discretization defines the minimum length of a heat pulse to the time step length, 
which was $0.4225 \mathrm{~s}$ in the $\mathrm{ZrB}_{2}$ experiments and $0.0997 \mathrm{~s}$ in the $\mathrm{C} / \mathrm{C}$ experiments. The heat flux amplitude is calculated by dividing $1 \mathrm{~J} \mathrm{~m}^{-2}$ by the respective time step length. This results in a heat flux amplitude of $2.37 \mathrm{~W} \mathrm{~m}^{-2}\left(\mathrm{ZrB}_{2}\right)$ or $10.03 \mathrm{~W} \mathrm{~m}^{-2}(\mathrm{C} / \mathrm{C})$.
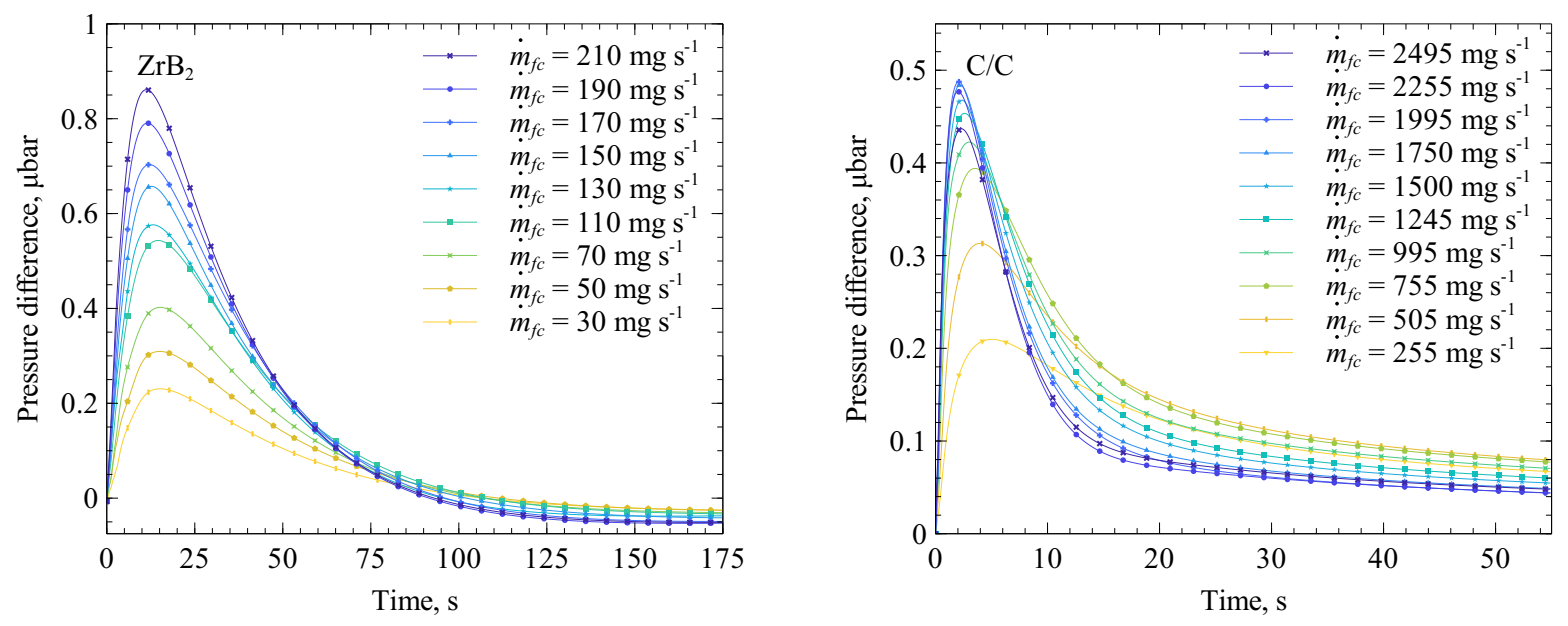

Fig. 3 Impulse responses for varying coolant mass flow rates calculated with the identified NISIp parameters and a $1 \mathrm{~J} \mathrm{~m}^{-2}$ impulse for the two transpiration cooling experiments with $\mathrm{ZrB}_{2}$ (left) and $\mathrm{C} / \mathrm{C}$ (right).

It can be observed in Fig. 3 that the impulse responses' peaks increase with coolant mass flow. For a clearer visualisation of this trend, the peak pressure values are plotted over the mass flow rate normalized to the maximum flow rate in Fig. 4 (blue lines). The peak pressure of the $\mathrm{ZrB}_{2}$ experiment increases nearly linearly with mass flow rate. The curve for the $\mathrm{C} / \mathrm{C}$ peak pressures is rather parabolic with its maximum at a normalized mass flow rate of 0.8 or $1995 \mathrm{mg} \mathrm{s}^{-1}$. The red lines in Fig. 4 are the time until the peak pressure is reached. Generally, this time is reached earlier with increasing mass flow rate. Also, the slope before and after the peak becomes steeper with increasing mass flow rate (cf. Fig. 3). The impulse responses are lower in magnitude for higher flow rates towards longer times (about $120 \mathrm{~s}$ for $\mathrm{ZrB} 2$ and $15 \mathrm{~s}$ for $\mathrm{C} / \mathrm{C}$ ). In summary, a higher mass flow rate generally leads to a higher peak pressure value, where the peak is reached earlier and the pressure falls off quicker after the peak.

The $\mathrm{ZrB}_{2}$ impulse responses (shown in Fig. 3) are not compared to the $\mathrm{C} / \mathrm{C}$ impulse responses any further, because the differences in the experimental setups, e.g. size of plenum volume, sample geometry and thermal insulation to the sides, are considered too significant. However, each data set is used as a reference for the validation of the numerical models described in section $\mathrm{V}$.

The $\mathrm{ZrB}_{2}$ impulse responses in Fig. 3 drop beneath their initial value after 100-125 s. This might be explained by too short cooling times between the single experiments in order to allow the system to cool down completely to its initial temperature. This would lead to a slightly elevated temperature and thus plenum pressure at the beginning of each measurement run. 


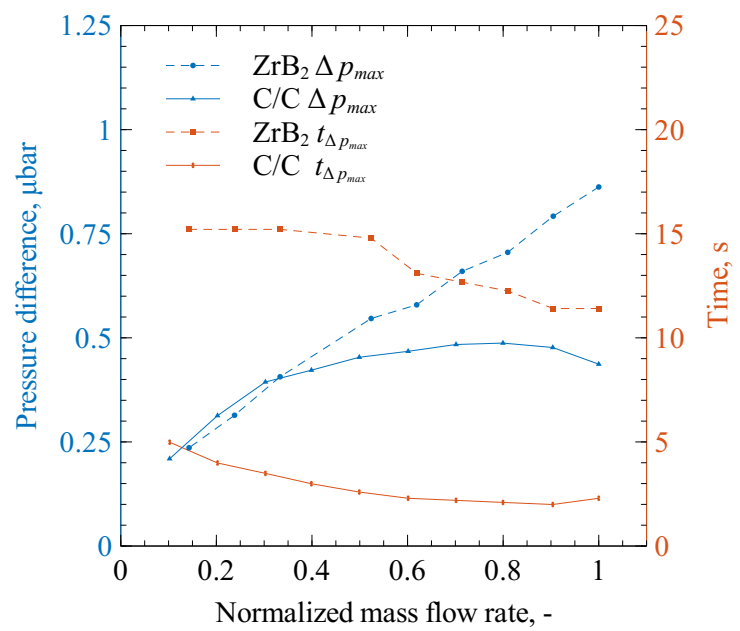

Fig. 4 Impulse responses' peak pressure and time until peak over normalized mass flow rate.

Heat losses through the sample's sides lead to a quicker decrease of solid temperature and thus plenum pressure. As mentioned in section III, this effect was counteracted by heating the structure around the porous sample with the calibration laser, too.

\section{Plenum Pressure Impulse Responses from Numerical Models}

Two simple numerical models of the transpiration cooling system have been developed to further analyse the measured pressure impulse response behavior. Both models calculate the temporal plenum pressure caused by an incident surface heat pulse but with different boundary conditions. One model, the transient temperature field model (model TTF), assumes a constant mass flow rate through the porous sample and calculates the plenum pressure for a time- and space-varying fluid temperature in the porous wall by means of the Darcy-Forchheimer equation (Eq. (1)). The second model, the finite plenum volume model (model FPV), treats the plenum volume as the control volume and the time-varying plenum pressure is calculated from the ideal gas equation. The mass in the plenum varies based on the continuity condition as an effect of a discrepancy between in- and outbound mass flow rates. The inbound mass flow rate through the mass flow controller is actively regulated and thus constant, but the mass flow rate through the porous sample can vary over time. The mass flow rate through the porous sample is again calculated by means of the Darcy-Forchheimer equation, for a given pressure difference between the plenum and ambience. The numerical models are described separately in subsections V.B and V.C. In the next subsection, the calculation of mutually used parameters, i.e. viscosity and volumetric heat transfer coefficient, are laid out.

\section{A. Determination of Viscosity and Volumetric Heat Transfer Coefficient}

The viscosity of nitrogen $\left(\mathrm{ZrB}_{2}\right)$ and air $(\mathrm{C} / \mathrm{C})$ at a given fluid temperature $T_{f}$ is calculated using Sutherland's law. Here, model TTF calculates the local viscosity using the local fluid temperature (cf. subsection V.B). Model FPV 
assumes the porous wall as a thermally lumped wall and uses the mean fluid temperature therein for the calculation of the mean viscosity.

In both numerical models, the plenum pressure change is related to the fluid temperature by a change of the temperature dependent fluid properties. However, the heat pulse does not affect the fluid directly but instead causes the solid to heat up. The fluid is only heated indirectly by the solid [26]. The internal heat transfer $\dot{q}_{s, f}$ from solid to fluid is defined by

$$
\dot{q}_{s, f}=h_{v}\left(T_{s}-T_{f}\right) \Delta x
$$

where $\Delta x$ is the characteristic length in flow direction [28]. The scaling parameter in Eq. (5) is the volumetric heat transfer coefficient $h_{v}$. It has a major impact on both solid and fluid temperature and hence on the plenum pressure impulse response behavior. The assessment of $h_{v}$ for the investigated materials is laid out in the following.

According to Florio et al. [35], the Nusselt and Reynolds number can be expressed as a function of the Darcy permeability coefficient $K_{D}$ :

$$
\begin{aligned}
& N u_{\sqrt{K_{D}}}=\frac{h_{v, N u} K_{D}}{\lambda_{f}}, \\
& R e_{\sqrt{K_{D}}}=-\frac{\rho_{f} K_{D}^{1.5}}{\mu_{f}^{2} \Phi} \frac{\Delta P}{l}=\frac{\rho_{f} v \sqrt{K_{D}}}{\mu_{f}}=\frac{\dot{m}_{p s} \sqrt{K_{D}}}{\mu_{f} A},
\end{aligned}
$$

with the fluid's thermal conductivity $\lambda_{f}$, density $\rho_{f}$ and velocity $v=-\frac{K_{D}}{\mu_{f} \Phi} \frac{\Delta P}{l}=\frac{\dot{m}_{p s}}{\rho_{f} A}$. Florio et al. [35] give various correlations for Nusselt and Reynolds number. One correlation,

$$
N u_{\sqrt{K_{D}}}=2.22 \cdot 10^{-6}\left(\operatorname{Re} \sqrt{K_{D}}\right)^{0.703}
$$

has been used in comparable studies to assess the Nusselt number for $\mathrm{ZrB}_{2}$ and $\mathrm{C} / \mathrm{C}$ [11, 36]. Substitution of Eqs. (6) and (7) in Eq. (8) and rearrangement yields

$$
h_{v, N u}=2.22 \cdot 10^{-6} \frac{\lambda_{f}}{K_{D}}\left(\frac{\dot{m}_{p s} \sqrt{K_{D}}}{\mu_{f} A}\right)^{0.703}
$$

Figure 5 shows the resulting values of $h_{v, N u}$ for varying mass flow rate through the porous sample. For better comparability, the mass flow rate was normalized to the maximum mass flow rate. The viscosity for the calculation of $h_{v, N u}$ was calculated for the initial temperature of $295 \mathrm{~K}$ using Sutherland's law. The thermal conductivity $\lambda_{f}$ is $0.026 \mathrm{~W} \mathrm{~m}^{-1} \mathrm{~K}^{-1}$ for both coolants. The required material properties and geometry of the porous samples are listed in Table 1. 


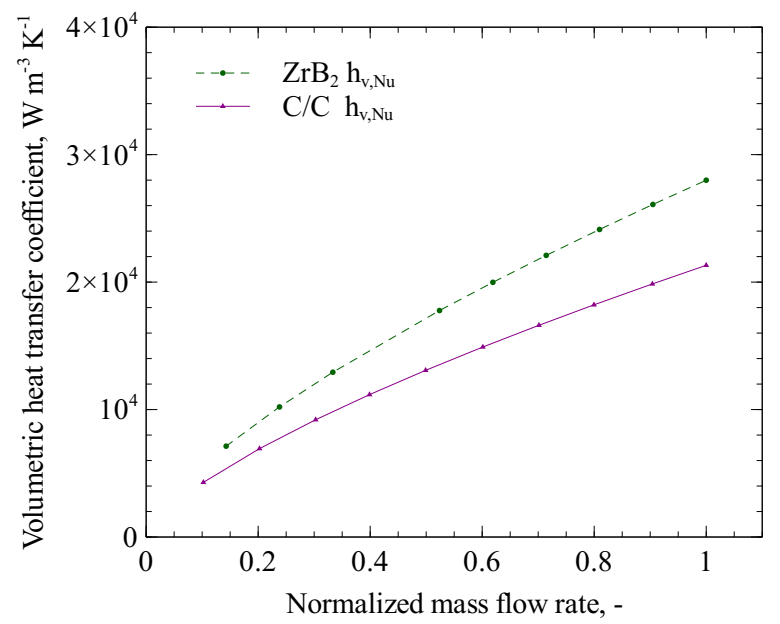

Fig. 5 Volumetric heat transfer coefficients from Eq. (9) vs. normalized coolant mass flow rate $\frac{\dot{m}}{\dot{m}_{\max }}$.

\section{B. Transient Temperature Field Model - Model TTF}

The transient temperature field model, model TTF, allows the analysis of the effect of a transient temperature field within the porous wall on the plenum pressure impulse response. The left hand side of the Darcy-Forchheimer equation Eq. (1) describes the pressure gradient and the pressure as a function of time across the porous sample. This is depending on the temperature distribution $T(x, t)$, i.e. the right hand side of Eq. (1). The question that is addressed in this subsection is whether the behavior of the experimentally obtained plenum pressure impulse responses can be explained through an uneven and equalizing fluid temperature field within the porous wall only. The transient temperature field model was designed for this investigation. Its layout is described in subsection V.B.1. The plenum pressure impulse responses calculated from model TTF are presented and discussed in subsection V.B.2.

\section{Composition of Model TTF}

A schematic of model TTF is depicted in Fig. 6. The porous wall is discretized into cells. In each time step the plenum pressure is calculated by

$$
\begin{array}{r}
p_{p l}\left(n_{t}\right)=p_{a m b}+\sum_{n_{x}=1}^{N_{x}} \Delta p\left(n_{x}, n_{t}\right)=p_{a m b}+\sum_{n_{x}=1}^{N_{x}}\left(\frac{\Delta l}{p\left(n_{x}, n_{t}\right)}\left(\frac{\mu_{f}\left(n_{x}, n_{t}\right) \dot{m}_{p s} R T_{f}\left(n_{x}, n_{t}\right)}{K_{D} A}+\frac{\dot{m}_{p s}^{2} R T_{f}\left(n_{x}, n_{t}\right)}{K_{F} A^{2}}\right)\right), \\
1 \leq n_{x} \leq N_{x}, \quad 1 \leq n_{t} \leq N_{t}
\end{array}
$$

with the spatial and temporal counters $n_{x}$ and $n_{t}$. The sum term in Eq. (10) calculates the pressure difference in each cell by means of the Darcy-Forchheimer equation. The last cell, i.e. $n_{x}=N_{x}$, represents the porous sample's backside (cf. $x=L$ in Fig. 1). The first cell, i.e. $n_{x}=1$, correlates to the surface $(x=0)$. The cell length $\Delta l$ was defined as $0.1 \mathrm{~mm}$ for both materials, which yields a total cell count $N_{x}$ of 50 and 112 for the $\mathrm{ZrB}_{2}$ and $\mathrm{C} / \mathrm{C}$ simulations respectively. The 
temporal discretisation was set to 50 and $14 \mu \mathrm{s}$ for $\mathrm{ZrB}_{2}$ and $\mathrm{C} / \mathrm{C}$ respectively. In both cases the time discretisation is shorter than the penetration time $\Delta t=\left(\frac{\Delta l}{3.6}\right)^{2} \frac{\rho_{s} c_{p, s}}{\lambda_{s}}$ for the given $\Delta l$ [37]. The heat wave propagation is thus not limited by the temporal discretisation.
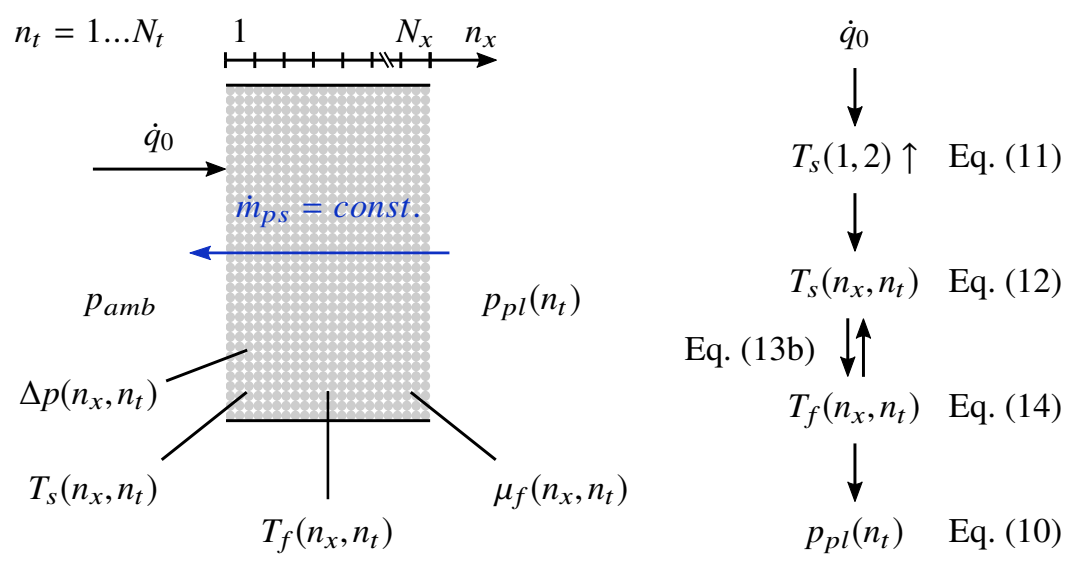

Fig. 6 Schematic of the transient temperature model (TTF).

The denotation $\dot{m}_{p s}$ in Fig. 6 and Eq. (10) means the mass flow rate through the porous sample. This specification was made because in model FPV (subsection V.C) the mass flow rate through the porous sample and the mass flow controller are allowed to be different.

In the first time $\operatorname{step}\left(n_{t}=1 \widehat{=} t=0 \mathrm{~s}\right)$, fluid and solid are in thermal equilibrium, i.e. $T_{f}\left(n_{x}, 1\right)=T_{s}\left(n_{x}, 1\right)=295 \mathrm{~K}$ for $1 \leq n_{x} \leq N_{x}$. The heat pulse is applied in the second time step $n_{t}=2$ by increasing the solid temperature of the first cell $n_{x}=1$ by

$$
T_{s}(1,2)=T_{s}(1,1)+\frac{\delta}{\rho_{s, e} \Delta l c_{p, s}}
$$

with the heat impulse $\delta$ with the heat density $1 \mathrm{~J} \mathrm{~m}^{-2}$. This heat is distributed into solid and fluid beginning with the third time step. Similar to [11], the solid energy balance for each cell and time step is calculated by

$$
T_{s}\left(n_{x}, n_{t}\right)=T_{s}\left(n_{x}, n_{t}-1\right)+\left(\dot{q}_{s}\left(n_{x}-1, n_{t}\right)-\dot{q}_{s}\left(n_{x}, n_{t}\right)-\dot{q}_{s, f}\left(n_{x}, n_{t}\right)\right) \frac{\Delta t}{\rho_{s, e} c_{p, s} \Delta l}, \quad 1 \leq n_{x} \leq N_{x}, \quad 3 \leq n_{t} \leq N_{t}
$$

with the conductive heat flux within the solid $\dot{q}_{s}\left(n_{x}, n_{t}\right)$ and the convective heat flux between fluid and solid $\dot{q}_{s, f}\left(n_{x}, n_{t}\right)$ defined by

$$
\begin{aligned}
\dot{q}_{s}\left(n_{x}, n_{t}\right)=\frac{\lambda_{s, e}\left(T_{s}\left(n_{x}, n_{t}-1\right)-T_{s}\left(n_{x}+1, n_{t}-1\right)\right)}{\Delta l}, & 1 \leq n_{x} \leq N_{x}-1, & 3 \leq n_{t} \leq N_{t} \\
\dot{q}_{s, f}\left(n_{x}, n_{t}\right)=h_{v}\left(T_{s}\left(n_{x}, n_{t}-1\right)-T_{f}\left(n_{x}, n_{t}-1\right)\right) \Delta l, & 1 \leq n_{x} \leq N_{x}, & 3 \leq n_{t} \leq N_{t} .
\end{aligned}
$$


The front and rear of the solid are assumed adiabatic, i.e. $\dot{q}_{s}\left(0, n_{t}\right)=\dot{q}_{s}\left(N_{x}, n_{t}\right)=0$ for $1 \leq n_{t} \leq N_{t}$. Accordingly, the fluid energy balance is

$T_{f}\left(n_{x}, n_{t}\right)=T_{f}\left(n_{x}, n_{t}-1\right)+\left(\dot{q}_{s, f}\left(n_{x}, n_{t}\right)-\dot{q}_{f, c o n v}\left(n_{x}, n_{t}\right)\right) \frac{\Delta t}{\rho_{f, e}\left(n_{x}, n_{t}-1\right) c_{p, f} \Delta l}, \quad 1 \leq n_{x} \leq N_{x}, \quad 3 \leq n_{t} \leq N_{t}$

with the heat flux due to convection of fluid through the porous wall

$$
\dot{q}_{f, \mathrm{conv}}\left(n_{x}, n_{t}\right)=\frac{\left(T_{f}\left(n_{x}, n_{t}-1\right)-T_{f}\left(n_{x}+1, n_{t}-1\right)\right) \dot{m}_{p s} c_{p, f}}{A}, \quad 1 \leq n_{x} \leq N_{x}, \quad 3 \leq n_{t} \leq N_{t},
$$

where $T_{f}\left(N_{x}+1, n_{t}\right)$ equals the constant plenum fluid temperature $T_{f, p l}=295 \mathrm{~K}$ for $1 \leq n_{t} \leq N_{t}$ [11]. The convective heat flux $\dot{q}_{s, f}\left(n_{x}, n_{t}\right)$ gained by the coolant equals the convective heat flux loss from the porous material and is thus also defined by Eq. (13b). $\rho_{f, e}\left(n_{x}, n_{t}\right)$ in Eq. (14) means the effective local fluid density, which is calculated by $\rho_{f, e}\left(n_{x}, n_{t}\right)=\Phi \rho_{f}\left(n_{x}, n_{t}\right)$ [28]. The local fluid density is calculated from the ideal gas equation $\rho_{f}\left(n_{x}, n_{t}\right)=\frac{p\left(n_{x}, n_{t}\right)}{R T_{f}\left(n_{x}, n_{t}\right)}$. The viscosity $\mu\left(x_{n}, x_{t}\right)$ is calculated in each time step by means of Sutherland's law using the current fluid temperature $T_{f}\left(x_{n}, x_{t}\right)$. Figure 5 gives the used $h_{v}$ values as a function of mass flow rate. In both experiments, $c_{p, f}$ is $1005 \mathrm{~J} \mathrm{~kg}^{-1} \mathrm{~K}^{-1}$. Table 1 gives the material properties and geometry of the porous samples which were used for the simulations with model TTF. Heat conduction within the fluid and radiative heat transfer were neglected.

\section{Plenum Pressure Impulse Responses from Model TTF}

Figure 7 shows plenum pressure impulse responses calculated by means of model TTF (cf. subsection V.B). The driving effect in these simulations is the transient temperature field of both solid and fluid. The plenum pressure is calculated in each time step individually for the current fluid temperature field. It can be observed in Fig. 7 that the plenum pressure impulse responses do not increase instantaneously to their peak. This initial plenum pressure increase is a result of the thermal energy within the solid being concentrated close to the surface. Thus, the fluid travels a short distance through the hot part of the porous wall and does not heat up as much as in later time steps, where the heat has penetrated deeper into the solid. As a consequence, the plenum pressure is lower magnitude in the first time steps. In conclusion: the non-uniform solid temperature field results in a lower plenum pressure.

A defining parameter in the process of solid temperature field relaxation is the penetration time, i.e. the duration a heat pulse needs to travel through the wall. According to Kaviany [37], the penetration time is calculated by

$$
t=\left(\frac{x}{3.6}\right)^{2} \frac{\rho_{s, e} c_{p, s}}{\lambda_{s, e}}
$$

The time for the thermal pulse to reach the backside of the porous sample $(x=L)$ is $0.12 \mathrm{~s}$ in the $\mathrm{ZrB}_{2}$ sample and $7.2 \mathrm{~s}$ for the $\mathrm{C} / \mathrm{C}$ sample. A short penetration time results in a fast stabilisation of the solid temperature field, which means 

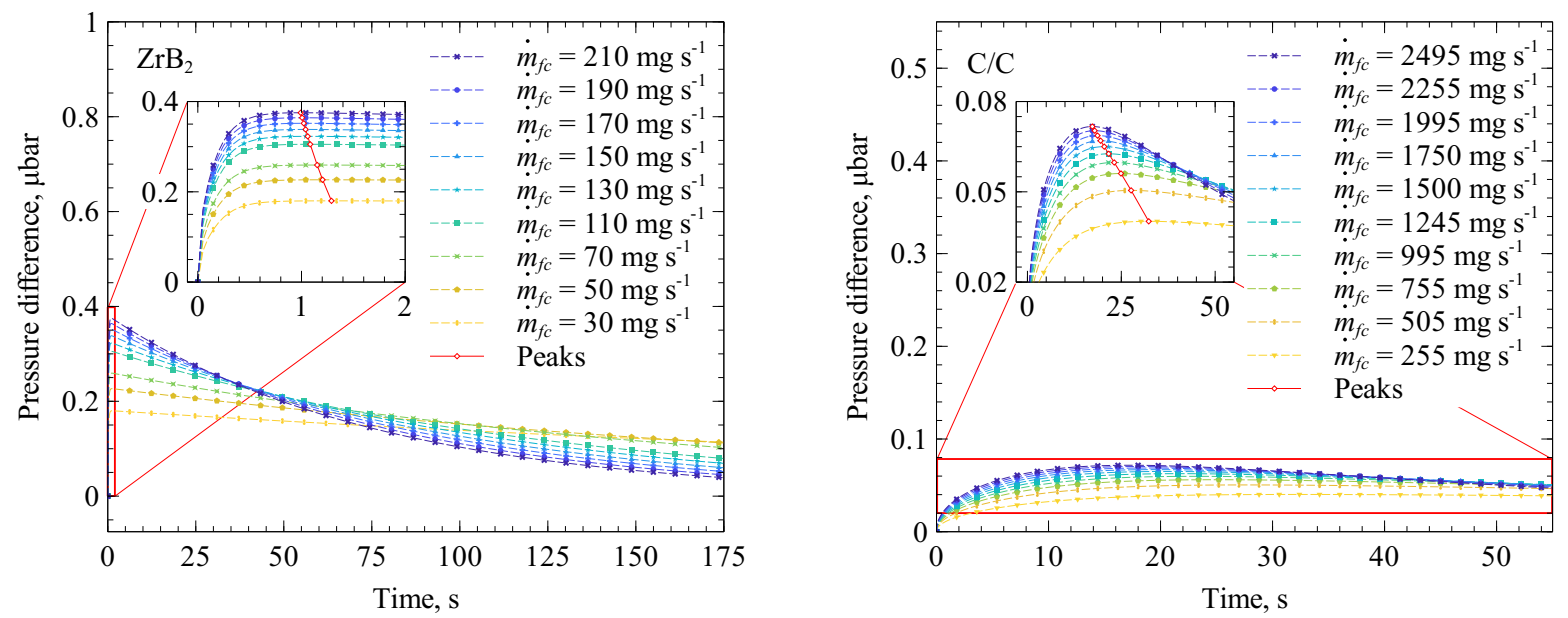

Fig. 7 Plenum pressure impulse responses for transient temperature model - model TTF; $\mathrm{ZrB}_{2}$ (left), C/C (right).

that the impulse response peaks quickly. This is confirmed by the simulation data shown in Fig. 7, where the $\mathrm{ZrB}_{2}$ impulse responses reach the peaks quicker than the $\mathrm{C} / \mathrm{C}$ impulse responses.

Figure 7 shows that the peak values of the impulse responses are increasing with mass flow rate for both materials. This is consistent with the experimental data shown in Fig. 3. This behavior can be explained by considering the energy balance in Eq. (14). It is driven by two counteracting heat flux terms: fluid and solid heat exchange $\dot{q}_{s, f}\left(n_{x}, n_{t}\right)$, which heats the fluid, and heat loss due to fluid convection $\dot{q}_{f, \text { conv }}\left(n_{x}, n_{t}\right)$, which cools the fluid. The latter is driven by the mass flow rate and the former by $h_{v}$. According to Florio et al. [35], $h_{v}$ is also a function of mass flow rate. $h_{v}$ increases with mass flow rate as can be seen in Fig. 5. This means that both $\dot{q}_{s, f}\left(n_{x}, n_{t}\right)$ and $\dot{q}_{f, c o n v}\left(n_{x}, n_{t}\right)$ are increasing with mass flow rate. In combination, $\dot{q}_{f, \text { conv }}\left(n_{x}, n_{t}\right)$ dominates over $\dot{q}_{s, f}\left(n_{x}, n_{t}\right)$, which leads to a lower fluid temperature for higher mass flow rates. This in turn leads to a lower relative plenum pressure increase (relative to the initial plenum pressure). However, the absolute plenum pressure difference is the product of relative increase and initial value. The magnitude of initial plenum pressure increases stronger with increasing mass flow rate than the relative plenum pressure decreases. In total, this results in the absolute plenum pressure difference to increase with mass flow rate (cf. Fig. 7). In conclusion, an increase in mass flow rate

- decreases the fluid temperature and with it the relative plenum pressure difference,

- increases $h_{v}$, which damps the fluid temperature and relative plenum pressure difference decrease,

- and increases the initial plenum pressure.

The combination of these three results in a higher absolute plenum pressure difference for higher mass flow rates.

The impulse responses in Fig. 7 reach their respective peaks earlier for higher mass flow rates. Towards longer time, the magnitude of the pressure impulse responses is lower for higher flow rate. This is consistent with the increased cooling efficiency at higher mass flow rates, through which solid temperature decrease quicker [23, 25]. The reason is 
that a lower solid temperature leads to a lower fluid temperature and in turn to a lower plenum pressure. Both features are also observed in the experimental data in Fig. 3.

As laid out, model TTF can predict the qualitative behavior of mass flow rate and magnitude of pressure difference of the experimental impulse responses. However, neither magnitude nor timing of the impulse response peaks agree with the experimental data. Even by variation of key parameters, such as $h_{v}$ and $\lambda_{s, e}$, the experimental impulse responses cannot be matched. This suggests that another effect is involved in the fluidmechanical process. As argued in the next subsection, the volume of the plenum is significant.

\section{Transient Finite Plenum Volume Model - Model FPV}

The results in subsection V.B.2 show, that the behavior of the experimentally obtained plenum pressure impulse responses cannot be explained by only considering the fluidmechanical processes within the porous sample. Therefore, a different approach of calculating the plenum pressure impulse response is tried out in this subsection. In the heat conduction scenario of Fig. 1 a finite plenum volume is added, which is bounded at the backside by the mass flow controller. This model allows taking into account a change of mass flow rate through the porous sample at constant $\dot{m}_{f c}$. This discrepancy leads to a mass increase in the plenum, which effects the plenum pressure by the ideal gas law. This approach is derived in subsection V.C.1. Based on this enhanced approach, a numerical model, the finite plenum volume model (model FPV) was designed. Its composition is described in subsection V.C.2. The plenum pressure impulse responses calculated from model FPV are presented and discussed in subsection V.C.3.

\section{Theoretical Background to model FPV}

Figure 8 shows the extended heat conduction scenario. When considering the plenum itself as the control volume

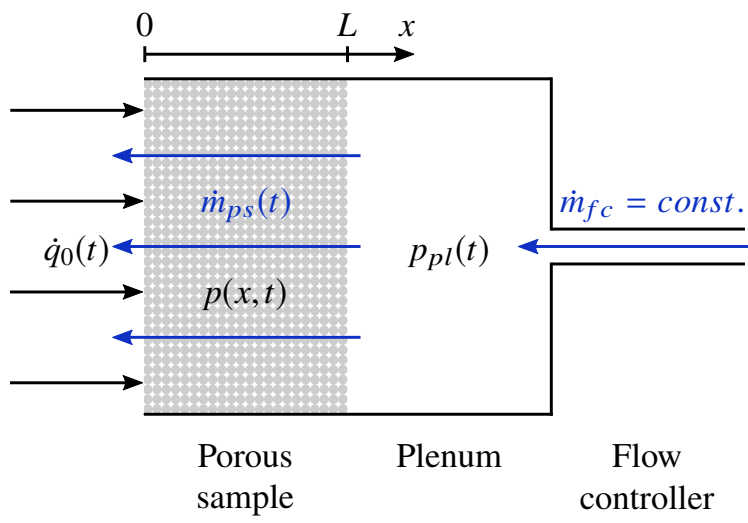

Fig. 8 Heat conduction scenario for a transpiration cooled porous material with finite plenum volume and variable mass flow rate through porous sample. 
and assuming the coolant inside the plenum as an ideal gas, the plenum pressure change to its initial condition is

$$
\Delta p_{p l}(t)=\Delta m_{f, p l}(t) \frac{R_{m} T_{f, p l}}{M_{f, p l} V_{p l}}
$$

with the plenum coolant's mass difference to its initial mass $\Delta m_{f, p l}(t)=m_{f, p l}(t)-m_{f, p l}(0)$ and the universal gas constant for an ideal gas $R_{m}$. The coolant's molar mass $M_{f, p l}$ and temperature $T_{f, p l}$ and the plenum volume $V_{p l}$ are assumed to be constant. Therefore, the temporal plenum pressure difference $\Delta p_{p l}(t)$ is a function of the temporal plenum coolant's mass difference $\Delta m_{f, p l}(t)$. This approach hence results in a discrepancy between the mass flow rates into and out of the plenum. The mass flow rate into the plenum is that through the flow controller $\dot{m}_{f c}$, the outflow is through the plenum side $(x=L)$ of the porous sample $\dot{m}_{p s}$. Consequently, at least one of the two must vary over time in order to cause a change in $m_{f, p l}(t)$. The porous sample is affected by the heat flux, which disturbs an otherwise stable initial flow condition, so that $\dot{m}_{p s}(t)$ varies over time, while $\dot{m}_{f c}$ remains constant. This extends the original heat conduction scenario by Loehle et al. [26], where $\dot{m}_{p s}$ is assumed constant. The rate at which the fluid mass in the plenum is changing is defined by

$$
\frac{d \Delta m_{f, p l}}{d t}(t)=\dot{m}_{f c}-\dot{m}_{p s}(t)
$$

and

$$
\dot{m}_{p s}(t)=\dot{m}_{p s}(0)+\Delta \dot{m}_{p s}(t)=\dot{m}_{f c}+\Delta \dot{m}_{p s}(t)
$$

with the flow rate difference to the initial condition $\Delta \dot{m}_{p s}(t)$ and the steady state initial condition $\dot{m}_{p s}(0)=\dot{m}_{f c}$. Substituting Eq. (19) in Eq. (18) yields that the change of coolant mass in the plenum can be interpreted as the inverse of the mass flow rate difference at the plenum side of the porous sample:

$$
\frac{d \Delta m_{f, p l}}{d t}(t)=-\Delta \dot{m}_{p s}(t)
$$

Integrating Eq. (20) yields

$$
\int_{0}^{t} \frac{d \Delta m_{f, p l}}{d \tau}(\tau) d \tau=\Delta m_{f, p l}(t)=-\int_{0}^{t} \Delta \dot{m}_{p s}(\tau) d \tau
$$

Substituting Eq. (21) into Eq. (17) yields

$$
\Delta p_{p l}(t)=-\frac{R_{m} T_{f, p l}}{M_{f, p l} V_{p l}} \int_{0}^{t} \Delta \dot{m}_{p s}(\tau) d \tau
$$


As can be seen from Eq. (22), the finite plenum volume approach correlates the plenum pressure change to a temporary flow rate fluctuation through the porous wall. It furthermore indicates that the plenum pressure difference is damped for an increasing plenum volume size.

\section{Composition of Model FPV}

The enhanced approach derived in the last subsection was translated into a numerical model: the finite plenum volume model - model FPV. A schematic of model FPV is depicted in Fig. 9. One major difference to model TTF is that
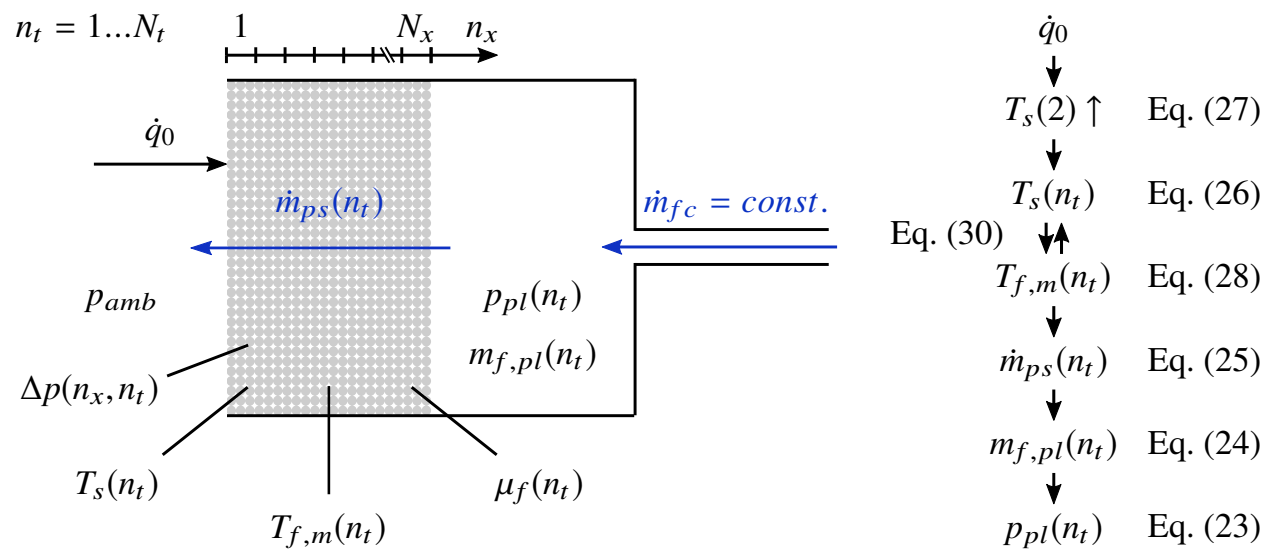

Fig. 9 Schematic of transient finite plenum volume model - model FPV.

the plenum pressure is not calculated from the Darcy-Forchheimer equation but from the ideal gas law:

$$
p_{p l}\left(n_{t}\right)=\frac{m_{f, p l}\left(n_{t}\right) R T_{f, p l}}{V_{p l}}, \quad 1 \leq n_{t} \leq N_{t}
$$

The plenum is hence modelled as a finite volume and acts as the control volume. The plenum fluid temperature $T_{f, p l}$ and volume $V_{p l}$ are assumed to remain constant, i.e. $T_{f, p l}=295 \mathrm{~K}$ and $V_{p l}=6.2 \cdot 10^{-4} \mathrm{~m}^{3}$ for $\mathrm{ZrB}_{2}$ and $V_{p l}=4.5 \cdot 10^{-4} \mathrm{~m}^{3}$ for C/C. The time-varying parameter in the right-hand side of Eq. (23) is the plenum fluid mass $m_{f, p l}\left(n_{t}\right)$. The initial plenum fluid mass $m_{f, p l}(1)$ is calculated by rearranging Eq. (23) and using the initial absolute plenum pressure $p_{p l}(1)$. It changes in the subsequent time steps due to a discrepancy between mass flow rate in and out:

$$
m_{f, p l}\left(n_{t}\right)=m_{f, p l}\left(n_{t}-1\right)+\left(\dot{m}_{f c}-\dot{m}_{p s}\left(n_{t}\right)\right) \Delta t, \quad 2 \leq n_{t} \leq N_{t}
$$

The time step width $\Delta t$ was set to $25 \mathrm{~ms}$ for $\mathrm{ZrB}_{2}$ and $5 \mathrm{~ms}$ for $\mathrm{C} / \mathrm{C}$. Model FPV assumes the mass flow rate through the mass flow controller $\dot{m}_{f c}$ to remain constant. The mass flow rate through the porous sample $\dot{m}_{p s}\left(n_{t}\right)$ is assumed to vary with time. This renders another major difference to model TTF, where $\dot{m}_{p s}$ is assumed constant. Model FPV 
determines $\dot{m}_{p s}\left(n_{t}\right)$ by iterating the plenum pressure calculated from the Darcy-Forchheimer equation to match the plenum pressure calculated by the ideal gas equation:

$$
\begin{aligned}
p_{p l}\left(n_{t}-1\right)= & \frac{m_{f, p l}\left(n_{t}-1\right) R T_{f, p l}}{V_{p l}} \\
= & p_{a m b}+\sum_{n_{x}=1}^{N_{x}}\left(\frac{\Delta l}{p\left(n_{x}, n_{t}-1\right)}\left(\frac{\mu_{f}\left(n_{t}-1\right) \dot{m}_{p s}\left(n_{t}\right) R T_{f, m}\left(n_{t}-1\right)}{K_{D} A}+\frac{\dot{m}_{p s}^{2}\left(n_{t}\right) R T_{f, m}\left(n_{t}-1\right)}{K_{F} A^{2}}\right)\right), \\
& 1 \leq n_{x} \leq N_{x}, \quad 2 \leq n_{t} \leq N_{t} .
\end{aligned}
$$

For this calculation, the porous wall is discretized into $N_{x}$ cells, where $N_{x}$ is 50 for the $\mathrm{ZrB}_{2}$ and 112 for the $\mathrm{C} / \mathrm{C}$ model respectively. The determination of $\dot{m}_{p s}\left(n_{t}\right)$ by means of Eq. (25) requires $T_{f, m}\left(n_{t}\right)$ and $\mu_{f}\left(n_{t}\right)$. Their determination is laid out in the following.

Model FPV assumes the porous material acts as a lumped thermal mass with a spatially uniform temperature (i.e. high Fourier number and low Biot number). Thus, with no coolant the porous material would obtain a steady state temperature difference of $\frac{\delta}{\rho_{s, e} c_{p, s} L}$ for an incident heat density $\delta$ of $1 \mathrm{~J} \mathrm{~m}^{-2}$. The inclusion of internal convection allows the material to be cooled. The energy balances for solid and fluid and the related heat flux terms are defined analogously to model TTF, but by omitting the spatial variable $n_{x}$, because the material is considered a lumped thermal mass. Hence, the solid energy balance is defined by

$$
T_{s}\left(n_{t}\right)=T_{s}\left(n_{t}-1\right)-\dot{q}_{s, f}\left(n_{t}-1\right) \frac{\Delta t}{\rho_{s, e} c_{p, s} L}, \quad 3 \leq n_{t} \leq N_{t}
$$

In the first time step, solid and fluid are in thermal equilibrium, i.e. $T_{s}(1)=T_{f, m}(1)=295 \mathrm{~K}$. The solid temperature is increased in the second time step by

$$
T_{S}(2)=T_{s}(1)+\frac{\delta}{\rho_{s, e} c_{p, s} L}
$$

The mean fluid energy balance is defined by

$$
T_{f, m}\left(n_{t}\right)=T_{f, i n}+\left(\dot{q}_{s, f}\left(n_{t}-1\right)-\dot{q}_{f, c o n v}\left(n_{t}-1\right)\right) \frac{\Delta t}{\rho_{f, e}\left(n_{t}-1\right) c_{p, f} L}, \quad 2 \leq n_{t} \leq N_{t},
$$

with the heat flux due to convection of the fluid

$$
\dot{q}_{f, \text { conv }}\left(n_{t}-1\right)=\frac{\left(T_{f}\left(n_{t}-1\right)-T_{f, \text { in }}\right) \dot{m}_{p s}\left(n_{t}\right) c_{p, f}}{A}, \quad 2 \leq n_{t} \leq N_{t}
$$

and the convective heat flux between fluid and solid

$$
\dot{q}_{s, f}\left(n_{t}\right)=h_{v}\left(T_{s}\left(n_{t}\right)-T_{f, m}\left(n_{t}\right)\right) L, \quad 1 \leq n_{t} \leq N_{t} .
$$


It can be seen from Eqs. (26) and (28) that the heat flux increase in the coolant equals the heat flux loss from the porous material. The fluid temperature at the entrance face of the porous sample $T_{f, \text { in }}$ equals the plenum fluid temperature $T_{f, p l}$, which is assumed to remain constant, i.e. $T_{f, i n}=T_{f, p l}=T_{s}(1)=T_{f, m}(1)=295 \mathrm{~K}$. Analogously to model TTF, the effective fluid density is calculated by $\rho_{f, e}\left(n_{t}\right)=\Phi \frac{p\left(n_{t}\right)}{R T_{f, m}\left(n_{t}\right)} \cdot c_{p, f}$ is $1005 \mathrm{~J} \mathrm{~kg}^{-1} \mathrm{~K}^{-1}$ for both coolants. Table 1 lists the used material properties and geometry of the porous samples. Figure 5 gives the used $h_{v}$ values as a function of mass flow rate. In the course of a simulation for a given mass flow rate, $h_{v}$ is assumed to remain constant (i.e. changes in Reynolds number are neglectable during the transient process). The viscosity is calculated for each time step by means of Sutherland's law and using the mean fluid temperature $T_{f, m}\left(n_{t}\right)$ from Eq. (28).

\section{Plenum Pressure Impulse Responses from Model FPV}

The plenum pressure impulse responses calculated by model FPV are shown in Fig. 10. The qualitative behavior of
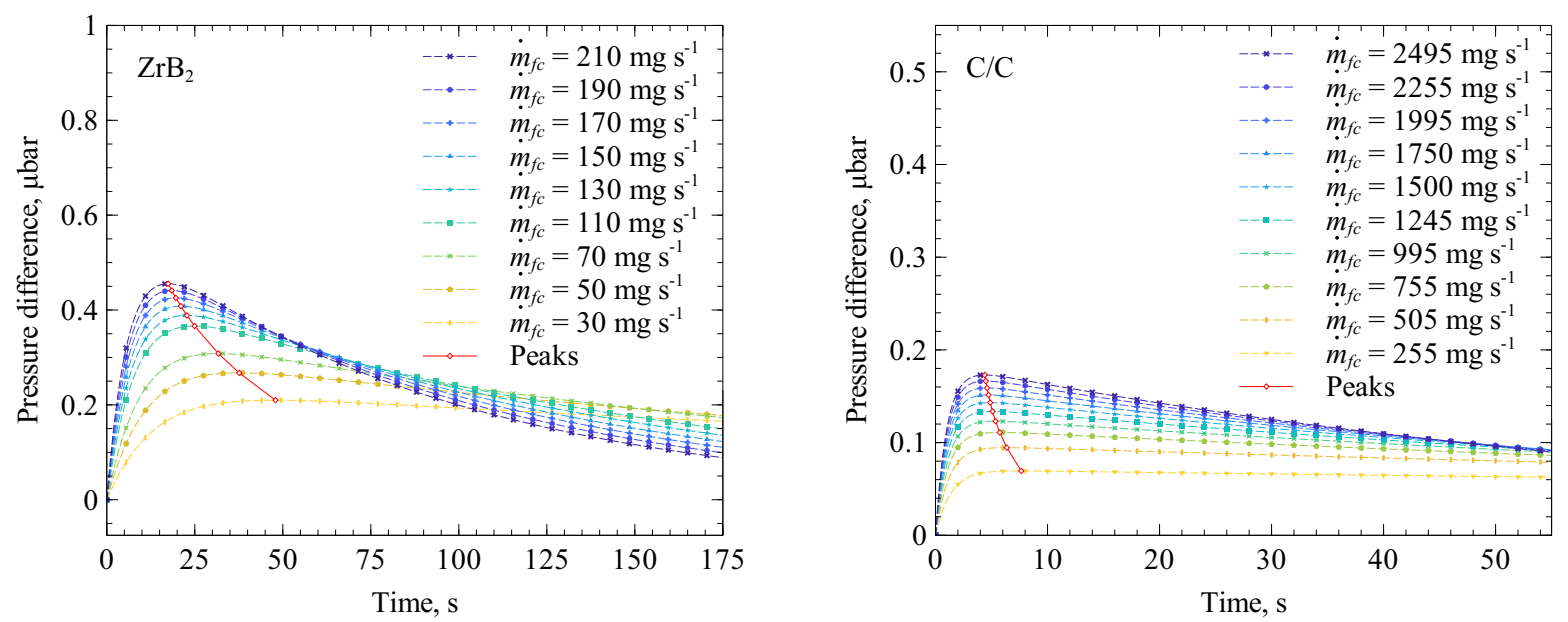

Fig. 10 Pressure impulse responses calculated with finite plenum volume model for $\mathrm{ZrB}_{2}$ (left) and $\mathrm{C} / \mathrm{C}$ (right).

the impulse responses is consistent with the experiments. The impulse response curve's maximum value is higher and reached earlier for increasing mass flow rates. Towards longer time, the magnitude is lower for higher flow rate for $\mathrm{ZrB}_{2}$. This also holds true for the $\mathrm{C} / \mathrm{C}$ curves, but not before $55 \mathrm{~s}$, which was chosen as the total impulse response length, equal to the experimental impulse responses. The simulated plenum pressure impulse responses show a qualitatively similar behavior as the experimental impulse responses and are in the same order of magnitude. This proves the validity of model FPV and hence its underlying assumption that the pressure increase is due to a mass flow rate drop through the porous sample. However, the simulated impulse responses in Fig. 10 do not represent the curves from the measurements using the assumed input parameters. Nonetheless, based on model FPV, the experimental data can be rebuilt by fitting the model parameters $h_{v}$ and addition of an heat loss term. Figure 11 shows as a comparison of an impulse response from modified model FPV to the experimental data. Exemplarily, the curves for $\mathrm{ZrB}_{2}$ at $210 \mathrm{mg} \mathrm{s}^{-1}$ (left) and $\mathrm{C} / \mathrm{C}$ at $1245 \mathrm{mg} \mathrm{s}^{-1}$ (right) are depicted. It can be observed, that the curves match nicely. From this it is concluded that model 

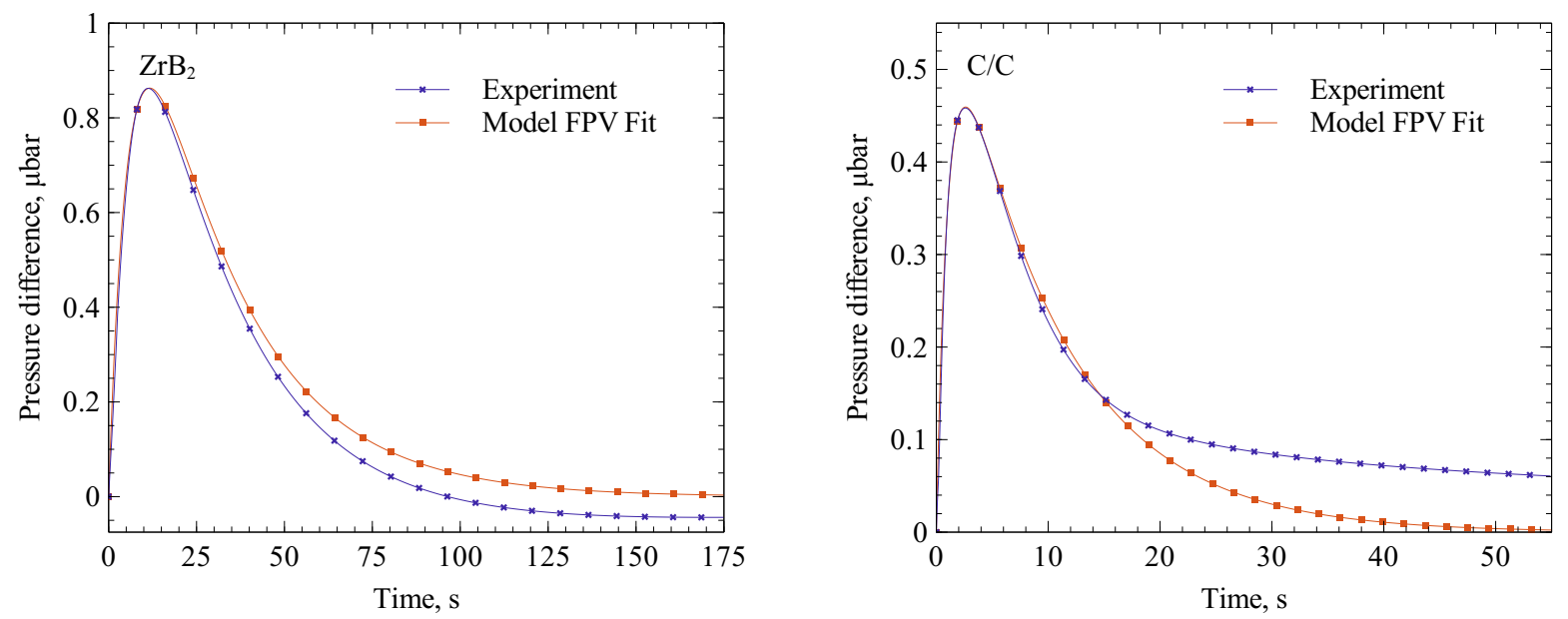

Fig. 11 Fit of impulse responses from model FPV to experimental curves for $\mathrm{ZrB}_{2}$ at $210 \mathrm{mg} \mathrm{s}^{-1}$ (left) and C/C at $1245 \mathrm{mg} \mathrm{s}^{-1}$ (right) by variation of $h_{v}$ and heat loss factor.

FPV and the underlying assumptions are valid and pose a valuable extension of the only phenomenological explanation by Loehle et al. [26].

The resulting fit parameters for the numerical impulse response in Fig. 11 are listed in Table 2. The reason $h_{v}$ was scaled and an additional heat loss factor was introduced as well as their magnitude are discussed in the following.

Table 2 Resulting $h_{v}$ value and heat loss factor $\psi$ from parameter fit for plenum pressure impulse responses shown in Fig. 11.

\begin{tabular}{lcc}
\hline & $h_{v}, \mathrm{~W} \mathrm{~m}^{-3} \mathrm{~K}^{-1}$ & $\psi$ \\
\hline $\mathrm{ZrB}_{2}$ at $210 \mathrm{mg} \mathrm{s}^{-1}$ & $1.1 \cdot 10^{6}$ & 0.01 \\
$\mathrm{C} / \mathrm{C}$ at $1245 \mathrm{mg} \mathrm{s}^{-1}$ & $2.0 \cdot 10^{6}$ & 0.07 \\
\hline
\end{tabular}

The variation of $h_{v}$ affects the impulse response by shifting the impulse response peaks to higher values and earlier times for increasing $h_{v}$ values. It was decided to use $h_{v}$ as a fit parameter, because the assessment of Florio et al. [35] may not be sufficiently suitable for the investigated materials. Here, the substitution of $\sqrt{K_{D}}$ for the characteristic length of the Reynolds number, which gives Eq. (7), is based on the assumption of a porous material consisting of a packed bed of spheres. The $\mathrm{C} / \mathrm{C}$ sample however is permeable due to internal cracks, which leads to a different flow condition within the sample [31]. Also, the $\mathrm{ZrB}_{2}$ sample consists of a bed of spheres, where the $\mathrm{ZrB}_{2}$ particles are partially melted together. This may explain why the fitted $h_{v}$ values are significantly higher than that of the assessment of Florio et al. [35] shown in Fig. 5, i.e. a factor of 40 for $\mathrm{ZrB}_{2}$ and 150 for $\mathrm{C} / \mathrm{C}$. The $h_{v}$ value for $\mathrm{C} / \mathrm{C}$ given in Table 2 is 5 times lower than the results of Schweikert, who found approximately $1 \cdot 10^{7} \mathrm{~W} \mathrm{~m}^{-3} \mathrm{~K}^{-1}$ [5]. The value for $\mathrm{ZrB}_{2}$ differs notably to the result of Hermann et al. who found approximately $6 \cdot 10^{4} \mathrm{~W} \mathrm{~m}^{-3} \mathrm{~K}^{-1}$ [36].

The heat loss term takes lateral heat losses into account and affects mainly the long term behavior of the impulse response. The scaling parameter is the heat loss factor $\psi$. For an increasing $\psi$, a given impulse response falls off steeper 
after its peak, because the solid and thus fluid temperature decreases quicker. In the numerical model, the heat loss term is added to the solid energy balance (Eq. (26)), which then reads

$$
T_{s}\left(n_{t}\right)=T_{s}\left(n_{t}-1\right)-\dot{q}_{s, f}\left(n_{t}-1\right) \frac{\Delta t}{\rho_{s, e} c_{p, s} L}-\left(T_{s}\left(n_{t}-1\right)-T_{s}(1)\right) \Delta t \psi \quad, \quad 3 \leq n_{t} \leq N_{t}
$$

This means that each second, $1 \%\left(\mathrm{ZrB}_{2}\right)$ and $7 \%(\mathrm{C} / \mathrm{C})$ of the solid temperature difference is conducted out of the system laterally. This is considered a reasonable quantity.

Eq. (22) indicates that the plenum pressure impulse response is damped for a larger plenum volume. This is confirmed by the data shown in Fig. 12. This figure shows impulse responses calculated from model FPV for various plenum volume sizes. Exemplarily only the curve for $\mathrm{C} / \mathrm{C}$ at $1245 \mathrm{mg} \mathrm{s}^{-1}$ is shown. In this calculation the values for $h_{v}$ and $\psi$ given in Table 2 were used. The reference plenum volume size is the same as in the experiment, i.e. $V_{p l, e x p}=$ $4.5 \cdot 10^{-4} \mathrm{~m}^{3}$. The data in Fig. 12 shows that a larger plenum volume both damps the magnitude of an impulse responses' peak pressure and delays the time until the peak is reached. The plenum volume size thus has also a time delaying effect.

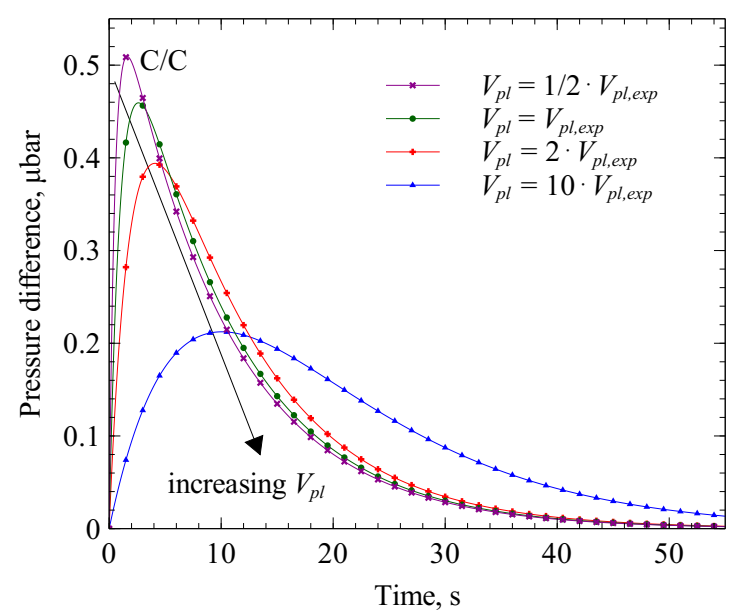

Fig. 12 Damping and time delaying effect of plenum volume size on plenum pressure impulse responses.

In summary, the experimental data can be well reproduced using model FPV. This means that, although the mass flow rate at the mass flow controller is constant, the mass flow rate through the porous sample cannot be assumed to remain constant when a heat flux is applied to the surface. Using model FPV, it was shown that the plenum volume size does influence the plenum pressure impulse response significantly by damping the impulse responses and shifting the peaks towards longer times. 


\section{Summary of Numerical Analyses}

Two numerical models have been developed which calculate the plenum pressure behavior due to an instantaneous temperature increase in different ways. Model TTF considers the porous wall as the control volume and determines a plenum pressure change as a result of a transient temperature field by means of the Darcy-Forchheimer equation. Model FPV considers the plenum volume as the control volume and calculates the continuous plenum pressure by the ideal gas law. Here, a mass flow rate fluctuation through the porous sample causes the mass in the plenum to change, which affects the pressure. Model TTF cannot reproduce the experimentally obtained impulse responses even by variation of key parameters such as $h_{v}$ or $\lambda_{s, e}$. This is only possible with model FPV.

\section{Conclusion}

This paper presents the analysis of plenum pressure change on surface heat flux for transpiration cooled environments. Two porous material samples have been experimentally tested in different setups and each for a set of coolant mass flow rates. For each flow rate, the system was identified by application of the Pressure-Based Non-Integer System Identification method NISIp. The peak values of the resulting plenum pressure impulse responses are found to increase with coolant mass flow rate. This means that a NISIp sensor is more sensitive with higher coolant mass flow rates.

Two numerical models have been developed for the analysis of the impulse response phenomena. The first model, model TTF, assumes a constant coolant mass flow through the porous sample and couples the plenum pressure only to the fluid temperature field inside the porous wall. It cannot explain the behavior of the experimentally obtained impulse responses accurately. The second model, model FPV, calculates the plenum pressure by means of the ideal gas law. Here, the plenum fluid mass changes due to a mass flow rate fluctuation through the porous wall, which is caused by a fluid temperature increase. The mass flow rate through the mass flow controller remains constant. The porous sample is modelled as a lumped thermal mass. With model FPV, the experimentally obtained impulse responses can be reproduced. From this it is concluded that the plenum pressure change is driven by a mass flow rate change through the porous wall. It was shown by means of model FPV that the plenum volume has a damping and time delaying effect on the plenum pressure behavior of a transiently heat loaded transpiration cooling system. This extends the phenomenological explanation by Loehle et al. [26] by an important aspect. The relevance of the mass flow rate and the plenum volume size entails that a NISIp sensor calibration must be made with the same mass flow rate and plenum volume as in the envisioned application. 


\section{Appendix}

\section{A. NISIp Parameters}

Table 3 NISIp parameters for the $\mathrm{ZrB}_{2}$ experiment

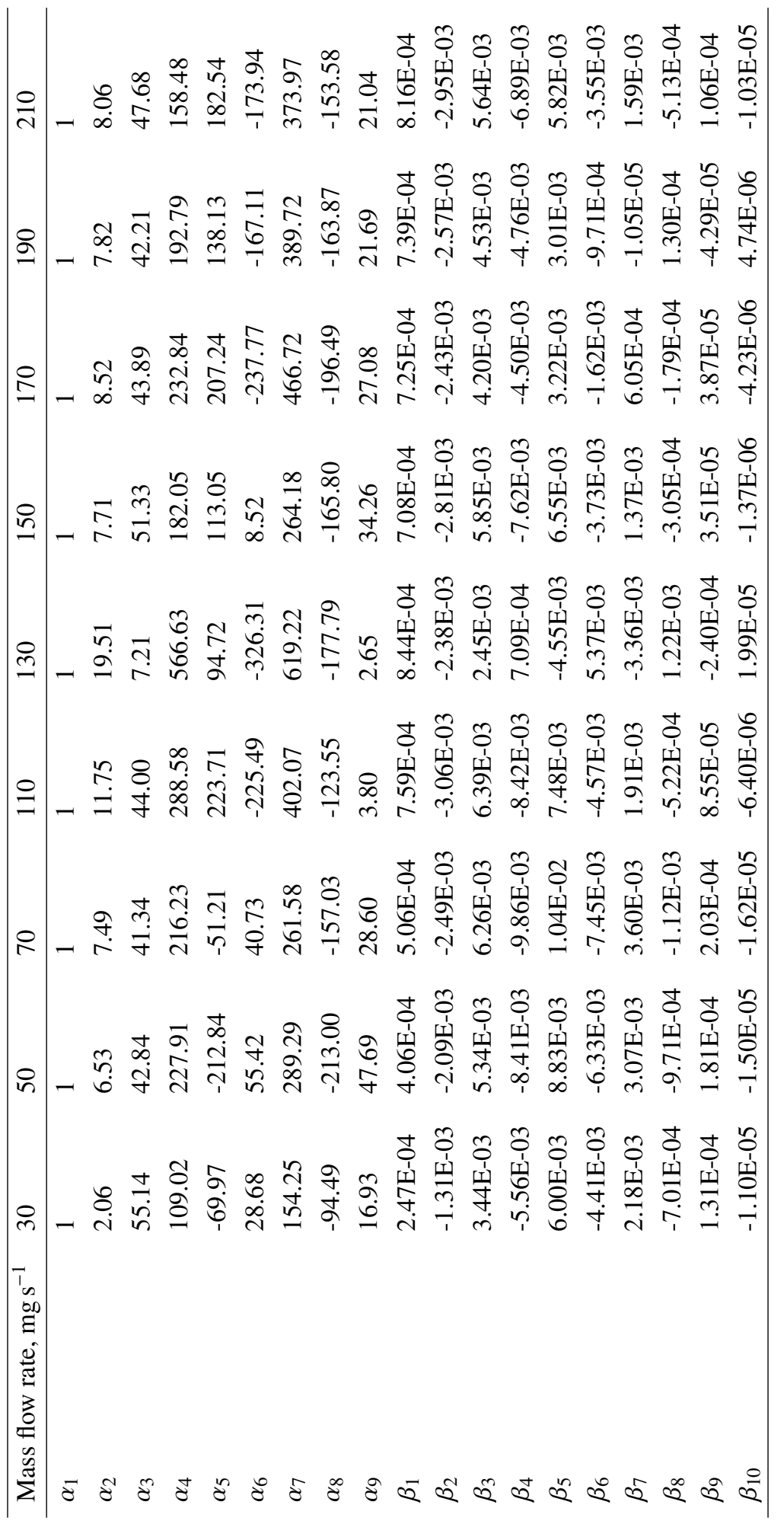


Table 4 NISIp parameters for the C/C experiment

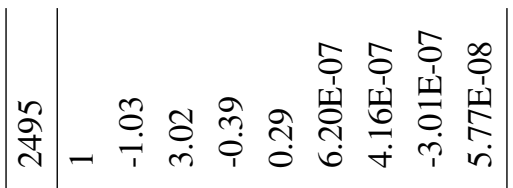

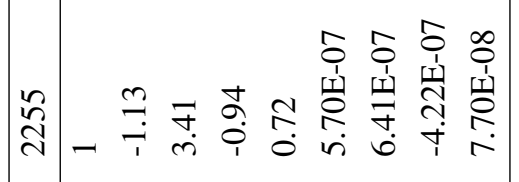

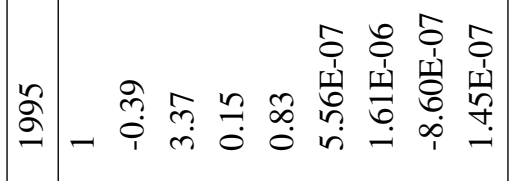

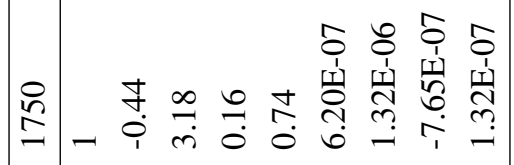

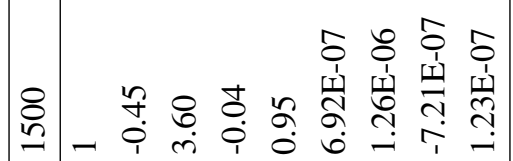

$$
\begin{aligned}
& \text { I }
\end{aligned}
$$

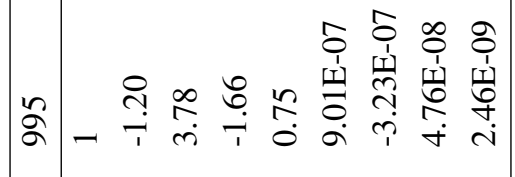

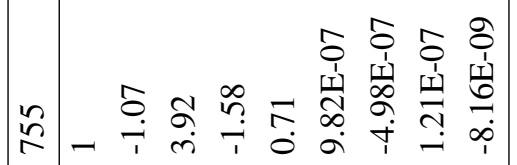

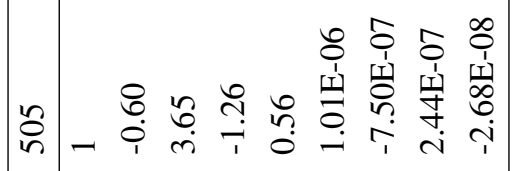

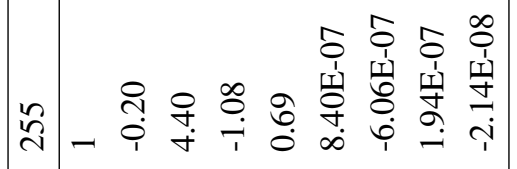

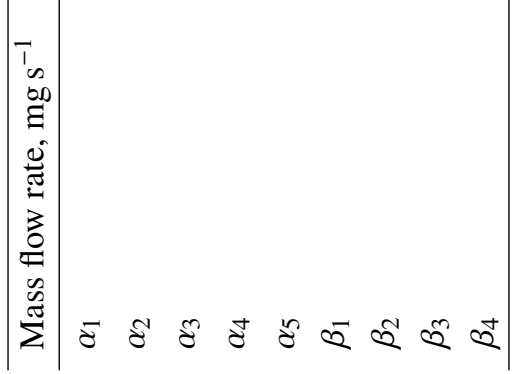




\section{Acknowledgments}

This work is partly funded through the ESA NPI Program under contract No. 4000121220/17/NL/MH. The funding by EPSRC (Reference: EP/P000878/1) is greatly acknowledged. The authors thank Laura Larrimbe, Daniel Glymond and Luc Vandeperre from Imperial College London for providing the material samples and the respective thermophysical properties. We thank the colleagues from the HEFDiG group for numerous fruitful discussions.

\section{References}

[1] Gupta, R. N., "Aerothermodynamic Analysis of Stardust Sample Return Capsule with Coupled Radiation and Ablation,” Journal of Spacecraft and Rockets, Vol. 37, No. 4, 2000, pp. 507-514.

[2] Anderson, J. D., Hypersonic and High-Temperature Gas Dynamics, $2^{\text {nd }}$ ed., AIAA Education Series, 2006.

[3] Arnold, R., Experimentelle Untersuchungen zur Filmkühlung in Raketenbrennkammern, Cuvillier, 2008.

[4] Selzer, M., Langener, T., Hald, H., and von Wolfersdorf, J., "Production and Characterization of Porous C/C Material," Tech. rep., DLR, 2009.

[5] Schweikert, S., "Ein Beitrag zur Beschreibung der Transpirationskühlung an keramischen Verbundwerkstoffen,” Dissertation, Universität Stuttgart, Institut für Thermodynamik der Luft- und Raumfahrt, 2019.

[6] Ifti, H. S., Hermann, T., and McGilvray, M., "Flow Characterisation of Transpiring Porous Media for Hypersonic Vehicles," 22nd AIAA International Space Planes and Hypersonics Systems and Technologies Conference, American Institute of Aeronautics and Astronautics, 2018. doi:10.2514/6.2018-5167, URL https://doi .org/10.2514/6.2018-5167.

[7] Steelant, J., "Achievements obtained on aero-thermal loaded materials for high-speed atmospheric vehicles within ATLLAS," 16th AIAA/DLR/DGLR International Space Planes and Hypersonic Systems and Technologies Conference, 2009, p. 7225.

[8] Steelant, J., Dalenbring, M., Kuhn, M., Bouchez, M., and von Wolfersdorf, J., “Achievements obtained within atllas-ii on aero-thermal loaded material investigations for high-speed vehicles," 21st AIAA International Space Planes and Hypersonics Technologies Conference, 2017, p. 2393.

[9] Bouchez, M., Dufour, E., Benezech, L., Cheuret, F., Steelant, J., Grenard, P., Redford, J., Sandham, N. D., Roberts, G. T., Passaro, A., Baccarella, D., Dalenbring, M., and Cavagna, L., "Multi-Level Coupled Simulations of Cooled Structures in the ATLLAS European Program,” 16th AIAA/DLR/DGLR International Space Planes and Hypersonic Systems and Technologies Conference, 2009, p. 7355.

[10] Bouchez, M., Dufour, E., Le Naour, B., Wilhelmi, C., Bubenheim, K., Kuhn, M., Mainzer, B., Riccius, J., Davoine, C., Justin, J. F., Axtmann, M., von Wolfersdorf, J., Spring, S., Villace, V. F., and Steelant, J., "Combustor Materials Research Studies for High Speed Aircraft in the European Program ATLLAS2," 20th AIAA International Space Planes and Hypersonic Systems and Technologies Conference, 2015, p. 3639. 
[11] Boehrk, H., Piol, O., and Kuhn, M., "Heat Balance of a Transpiration-Cooled Heat Shield," Journal of Thermophysics and Heat Transfer, Vol. 24, No. 3, 2010, pp. 581-588. doi:10.2514/1.47172, URL https ://doi .org/10.2514/1.47172.

[12] Hermann, T., McGilvray, M., and Naved, I., "Performance of Transpiration-Cooled Heat Shields for Reentry Vehicles," AIAA Journal, Vol. 58, No. 2, 2020, pp. 830-841. doi:10.2514/1.j058515, URL https://doi .org/10.2514/1.j058515.

[13] Cheuret, F., Mack, A., Murray, N., Steelant, J., and Langener, T., "Numerical investigations on transpiration cooling for scramjet applications using different coolants," 17th AIAA International Space Planes and Hypersonic Systems and Technologies Conference, 2011, p. 2379.

[14] Kuhn, M., Bouchez, M., Le Naour, B., Justin, J.-F., Van den Eynde, J., and Steelant, J., “Ceramic strut injection technologies for high-speed flight," 21st AIAA International Space Planes and Hypersonics Technologies Conference, 2017, p. 2416.

[15] Ozisik, M. N., Heat Conduction, $2^{\text {nd }}$ ed., Wiley, 1993.

[16] Beck, J., Blackwell, B., and St. Clair, C. R., Inverse Heat Conduction: Ill-posed Problems, Wiley, 1985. URL https: //www . thermalfluidscentral.org/e-books/book-intro.php?b=44.

[17] Alifanov, O. M., Inverse Heat Transfer Problems, Springer Science \& Business Media, Berlin Heidelberg, 2012.

[18] Loehle, S., and Fuchs, U., "Heat Flux Calibration Measurement Using Noninteger System Identification Method for Cooled Surfaces," AIAA Journal of Thermophysics and Heat Transfer, Vol. 25, No. 2, 2011, pp. 213-217. doi:10.2514/1.T3631.

[19] Battaglia, J.-L., Cois, O., Puigsegur, L., and Oustaloup, A., "Solving an Inverse Heat Conduction Problem Using a Non-integer Identified Model,” International Journal of Heat and Mass Transfer, Vol. 44, 2001, pp. 2671-2680.

[20] Loehle, S., Battaglia, J.-L., Batsale, J.-C., Enouf, O., Dubard, J., and Filtz, R.-R., "Characterization of a Heat Flux Sensor Using Short Pulse Laser Calibration,” Review of Scientific Instruments, Vol. 78, 2007.

[21] Gardarein, J.-L., Battaglia, J.-L., and Loehle, S., "Heat flux sensor calibration using noninteger system identification: Theory, experiment, and error analysis," Review of Scientific Instruments, Vol. 80, No. 025103, 2009. doi:10.1063/1.3079328.

[22] Ljung, L., System Identification: Theory for the user, Prentice Hall, 1987.

[23] Loehle, S., Fuchs, U., Digel, P., Hermann, T., and Battaglia, J.-L., "Analysing Inverse Heat Conduction Problems by the Analysis of the System Impulse Response," Inverse Problems in Science and Engineering, 2013. doi:10.1080/17415977.2013.780170, URL http://www . tandfonline.com/doi/abs/10.1080/17415977.2013.780170.

[24] Loehle, S., Battaglia, J.-L., Jullien, P., van Ootegem, B., Couzi, J., and Lasserre, J.-P., "Improvement of High Heat Flux Measurements using a null-point Calorimeter," Journal of Spacecrafts and Rockets, Vol. 45, No. 1, 2007, pp. 76-81.

[25] Hermann, T., McGilvray, M., Ifti, H. S., Hufgard, F., and Loehle, S., "Thermal Impulse Response in Porous Media for Transpiration-Cooling Systems," Journal of Thermophysics and Heat Transfer, Vol. 34, No. 2, 2020, pp. 447-456. doi:10.2514/1.t5841. 
[26] Loehle, S., Schweikert, S., and von Wolfersdorf, J., "Method for Heat Flux Determination of a Transpiration-Cooled Wall from Pressure Data," Journal of Thermophysics and Heat Transfer, Vol. 30, No. 3, 2016, pp. 567-572.

[27] Podlubny, I., Fractional Differential Equations, Academic Press, 1998.

[28] Nield, D. A., and Bejan, A., Convection in Porous Media, Springer International Publishing, 2017. doi:10.1007/978-3-31949562-0, URL https: //doi .org/10.1007/978-3-319-49562-0.

[29] Chase, M. W., "NIST-JANAF Thermochemical Tables," American Institute of Physics for the National Institute of Standards and Technology, 1998.

[30] Selzer, M., Schweikert, S., Boehrk, H., Hald, H., and von Wolfersdorf, J., "Comprehensive C/C sample characterizations for transpiration cooling applications,” Tech. rep., DLR, 2016.

[31] Hald, H., Herbertz, A., Kuhn, M., and Ortelt, M., “Technological Aspects of Transpiration Cooled Composite Structures for Thrust Chamber Applications," 16th AIAA/DLR/DGLR International Space Planes and Hypersonic Systems and Technologies Conference, American Institute of Aeronautics and Astronautics, 2009. doi:10.2514/6.2009-7222, URL https://doi .org/ $10.2514 / 6.2009-7222$.

[32] Ewenz Rocher, M., Hermann, T., McGilvray, M., Ifti, H. S., Hufgard, F., Eberhart, M., Meindl, A., Loehle, S., and Zander, F., “Testing a Transpiration Cooled Zirconium-Di-Boride sample in the Plasma Tunnel at IRS,” 2019 AIAA SciTech Forum, AIAA, 2019.

[33] Balat-Pichelin, M., Bêche, E., Sciti, D., and Alfano, D., "Emissivity, catalycity and microstructural characterization of ZrB2-SiCfiber based UHTC at high temperature in a non-equilibrium air plasma flow," Ceramics International, Vol. 40 , No. 7 Part A, 2014, pp. 9731-9742. doi:10.1016/j.ceramint.2014.02.059.

[34] Schweikert, S., Loehle, S., Selzer, M., Boehrk, H., and von Wolfersdorf, J., "Surface Heat Flux Determination of Transpiration Cooled C/C by the Application of Non-integer System Identification," 8th European Workshop on Thermal Protection and Hot Structures, ESA, 2016.

[35] Florio, J., Henderson, J. B., Test, F. L., and Hariharan, R., "Characterization of forced convection heat transfer in decomposing, glass-filled polymer composites,” Journal of composite materials, Vol. 25, No. 11, 1991, pp. 1515-1539.

[36] Hermann, T., McGilvray, M., Ifti, H. S., Hufgard, F., and Loehle, S., "Fluid-Solid Heat Exchange in Porous Media for Transpiration Cooling Systems,” 2019 AIAA SciTech Forum, American Institute of Aeronautics and Astronautics, 2019.

[37] Kaviany, M., Principles of Heat Transfer, John Wiley and Sons, 2001. 